Sánchez-Pardo, J. C., Blanco-Rotea, R., Costa-García, J.M., Sanjurjo-Sánchez, J., Barrientos-Rodríguez, V. y Alonso-Toucido, V. (2020): "Hacia una reinterpretación de la secuencia de ocupación del Yacimiento de a Cidadela (A Coruña)", Spal 29.1: 157-188. DOI: http://dx.doi.org/10.12795/spal.2020.i29.06

\title{
HACIA UNA REINTERPRETACIÓN DE LA SECUENCIA DE OCUPACIÓN DEL YACIMIENTO DE A CIDADELA (A CORUÑA)
}

\author{
TOWARDS A REINTERPRETATION OF THE ARCHAEOLOGICAL \\ SEQUENCE OF THE SITE OF A CIDADELA (A CORUÑA, SPAIN)
}

Dedicado a la memoria de nuestro maestro y amigo, José Manuel Caamaño Gesto

\author{
JOSÉ CARLOS SÁNCHEZ-PARDO
}

Responsable de la correspondencia

Investigador Ramón y Cajal. Departamento de Historia, Universidade de Santiago de Compostela

Laboratorio de Patrimonio, Paleoambiente e Paisaxe. Ed. Monte da Condesa s/n, 15782, Santiago de Compostela Correo-e: josecarlos.sanchez@usc.es. (1) https://orcid.org/0000-0003-2899-4951

Researcher ID: <https://publons.com/researcher/AAH-1559-2019>

\section{REBECA BLANCO-ROTEA}

Investigadora Posdoutoral da Xunta de Galicia. Departamento de Historia

Universidade de Santiago de Compostela. Laboratorio de Patrimonio, Paleoambiente e Paisaxe.

Ed. Monte da Condesa s/n, 15782, Santiago de Compostela. Investigadora visitante. Unidade de Arqueologia

Universidade do Minho. Edifício dos Congregados. Avda. Central, 100, 4710-229, Braga (Portugal)

Correo-e: rebeca.blanco.rotea@usc.es. (1) https://orcid.org/0000-0003-3975-2149

Researcher ID: <https://publons.com/researcher/B-2499-2018>

JOSÉ MANUEL COSTA-GARCÍA

Investigador Posdoutoral da Xunta de Galicia

Departamento de Historia, Universidade de Santiago de Compostela. Laboratorio de Patrimonio, Paleoambiente e Paisaxe Ed. Monte da Condesa s/n, 15782, Santiago de Compostela. Visiting Scholar. School of History, Classics and Archaeology

Faculty of Humanities and Social Sciences. Newcastle University, NE1 7RU (United Kingdom) Correo-e: josemanuel.costa@usc.es D https://orcid.org/0000-0002-0819-1361

Researcher ID: <https://publons.com/researcher/H-5584-2015>

\section{JORGE SANJURJO-SÁNCHEZ}

Profesor Contratado Doctor. Instituto Universitario de Geología - Grupo de investigación CULXEO, Universidade da Coruña Edificio de Servicios Centrales de Investigación. Campus de Elviña, 15071, A Coruña Correo-e: jsanjurjo@udc.es. (D https://orcid.org/0000-0002-7559-8647 Researcher ID: <https://publons.com/researcher/E-4404-2011>

VICTOR BARRIENTOS-RODRÍGUEZ

Profesor Contratado Doctor. Departamento de Ingeniería Civil - Grupo de investigación CULXEO, Universidade da Coruña Edificio de Servicios Centrales de Investigación. Campus de Elviña, 15071, A Coruña Correo-e: victor.barrientos@udc.es. D https://orcid.org/0000-0002-8004-2790 Researcher ID: <https://publons.com/researcher/AAH-2012-2019>

FRANCISCO ALONSO-TOUCIDO

Arqueólogo e investigador predoctoral. Departamento de Historia, Universidade de Santiago de Compostela Laboratorio de Patrimonio, Paleoambiente e Paisaxe. Ed. Monte da Condesa s/n, 15782, Santiago de Compostela Correo-e: franalonsotoucido@hotmail.com. (D) https://orcid.org/0000-0003-2554-5448 Researcher ID: <https://publons.com/researcher/K-2841-2018> 
Resumen: Se presentan los resultados de un amplio trabajo interdisciplinar de revisión, análisis, datación y excavación del conocido yacimiento de A Cidadela (A Coruña). Tradicionalmente los esfuerzos investigadores en este yacimiento se habían centrado en la presencia de un fuerte romano (siglos II-III d.C), dejando de lado una serie de fases posteriores denominadas "germánicas". Con el objetivo de profundizar en el conocimiento de la secuencia completa del yacimiento publicamos en 2015 una lectura de paramentos de dos sectores del mismo. Continuando con ese trabajo, en este artículo se presentan los resultados de la revisión de materiales tardoantiguos y medievales, análisis de composición y procedencia del material pétreo, datación absoluta de un total de 21 muestras de morteros, carbones y sedimentos por radiocarbono y luminiscencia ópticamente estimulada y dos sondeos arqueológicos realizados en 2016. La combinación de toda esta nueva información cambia radicalmente nuestra visión y comprensión de las fases "posromanas" de A Cidadela con la detección de al menos cuatro horizontes arqueológicos posteriores al fuerte romano: tardoantiguo (ss. IV-VI/VII), altomedieval (ss. IX-XI), plenomedieval (s. XIII) y bajomedieval-moderno. A Cidadela se convierte así en un enclave privilegiado para analizar arqueológicamente la ocupación del interior de Galicia en los últimos 2000 años.

Palabras clave: Tardoantigüedad, fuerte romano, iglesia altomedieval, OSL, Geoarqueología, materiales de importación.

\section{INTRODUCCIÓN}

A Cidadela (Sobrado dos Monxes, A Coruña) es uno de los yacimientos más conocidos e intervenidos de la arqueología gallega. Se sitúa sobre un altozano entre los ríos Cabalar y Pequeño (fig. 1), lugar donde la existencia de restos arqueológicos es públicamente conocida desde al menos principios del siglo XX (Costa-García 2014). Aunque en la década de 1930 se desarrollaron las primeras intervenciones arqueológicas en el yacimiento (Del Castillo López 1934, 1935), no fue hasta 1981 cuando, bajo la dirección de J. M. Caamaño Gesto (1984), se iniciaron las excavaciones sistemáticas que supondrían un importante avance en el conocimiento del sitio.

Gracias a estos trabajos, prolongados hasta la década de 2000, sabemos que en época romana se construyó un fuerte auxiliar ocupado por la cohors I Celtiberorum (Caamaño Gesto 1989). Las excavaciones han permitido exhumar casi el 20\% del asentamiento, habiéndose prestado especial atención a las edificaciones situadas en el centro del recinto militar -los denominados latera praetorii- $\mathrm{y}$ al sector oeste de su sistema defensivo
Abstract: This paper presents the results of an extensive interdisciplinary work of revision, analysis, dating and excavation of the well known site of A Cidadela (A Coruna). Research on this site has traditionally focused on the presence of a Roman fort (2nd-3rd centuries AD), leaving aside a series of later phases known as "Germanic". In order to deepen our knowledge of the whole sequence of the site, we published in 2015 an stratigraphical analysis of two sectors. Continuing this work, this article presents the results of the review of the late antique and medieval material record, petrological analysis of rocks, absolute dating of 21 samples of mortars, charcoal and sediments by means of radiocarbon and optically stimulated luminescence and two archaeological surveys conducted in 2016. The combination of all this new information radically changes our vision and understanding of the "post-Roman" phases of A Cidadela with the detection of at least four archaeological horizons after the Roman fort: late antique $\left(4^{\text {th }}-6^{\text {th }} / 7^{\text {th }}\right.$ centuries $\left.A D\right)$, late medieval $\left(9^{\text {th }}-11^{\text {th }}\right.$ centuries AD), Central Middle Ages ( $13^{\text {th }}$ century AD) and Late Medieval-Modern times. A Cidadela thus became a privileged place for the archaeological analysis of the occupation of inland Galicia in the last 2000 years.

Keywords: Late Antiquity, roman camp, early medieval church, OSL, Geoarchaeology, imported materials.

(Caamaño Gesto 1997, Caamaño Gesto y Fernández Rodríguez 2002, Ramil González et al. 2013) (fig. 2). Asimismo, diversas publicaciones han abordado aspectos relativos a la arquitectura y organización interna del asentamiento militar romano, su cultura material, o la relación de éste con su entorno (Caamaño Gesto et al. 2000, Caamaño Gesto y Fernández Rodríguez 2006, Costa-García 2010, López Pérez 2006).

Sin embargo, ya desde las primeras excavaciones fueron identificados determinados elementos materiales y estructurales que excedían el marco cronológico habitualmente barajado para esta ocupación militar -entre los siglos II y IV d.C. -. Estas evidencias nunca se estudiaron de forma detallada, pero a lo largo de los últimos 30 años se fueron integrando en una secuencia general explicativa para el yacimiento (Caamaño Gesto y Fernández Rodríguez 2006, Costa-García y Varela Gómez 2011). Dicha secuencia considera que tras el abandono del recinto militar se habría producido una ocupación puntual en época tardoantigua (siglos IV-VI d.C.). Después de un breve hiato, un nuevo grupo humano se habría asentado aquí en el siglo VII d.C. Esta ocupación, 


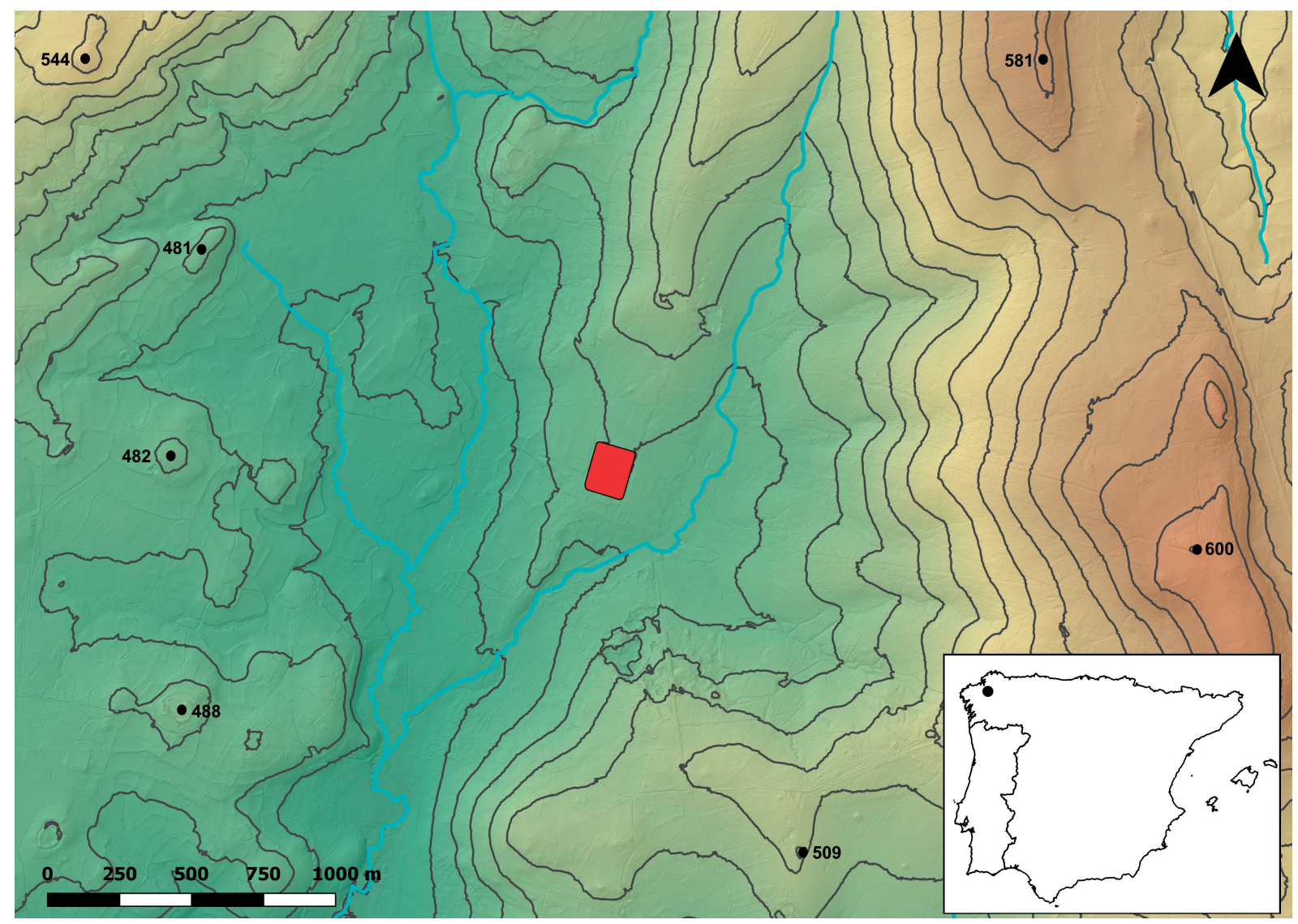

Figura 1. Localización de yacimiento sobre modelo digital del terreno LiDAR 1m. Curvas de nivel cada 10 m. (Base cartográfica del Instituto Geográfico Nacional)..

denominada "germánica", se caracterizaría por la fuerte reorganización del espacio y la construcción de una iglesia, posiblemente monástica y con dependencias a su alrededor, en el sector central del antiguo recinto militar. Finalmente, algunas estructuras dispersas en el yacimiento pertenecerían a una fase "medieval" poco definida (Fernández Rodríguez 1997). En relación con ella, una mención en un documento del cercano monasterio de Sobrado (Loscertales 1976: doc. 137) avalaría la existencia de una iglesia en A Cidadela en el año 995, tradicionalmente identificada con el templo parroquial hoy sito extramuros.

Con el objetivo de profundizar en el conocimiento de las llamadas fases "germánica" y "medieval" del yacimiento, entre los años 2014 y 2017 se llevaron a cabo diversas iniciativas en el marco del proyecto EMCHAHE (Sánchez-Pardo y Blanco-Rotea 2014). En una primera fase, se procedió a la revisión de toda la información documental disponible sobre el yacimiento con el fin de reconstruir la secuencia de ocupación del mismo. La complejidad de este proceso, agudizada por la heterogeneidad y carácter parcial de los datos disponibles, nos llevó a centrarnos en el estudio de dos sectores de especial interés en los que se habían documentado actividades "posromanas": el espacio situado al noroeste de la antigua via principalis del fuerte romano, y el área correspondiente a la supuesta iglesia "germánica" (fig. 2). En ellos se llevó a cabo una lectura de paramentos que nos permitió establecer una nueva secuencia y cronología relativa de ocupación del yacimiento (Blanco-Rotea et al. 2015).

Tras la publicación de este primer trabajo, en los dos últimos años hemos centrado nuestros esfuerzos en caracterizar y datar con precisión cada una de las fases identificadas. Para ello, se tomaron muestras de morteros, carbones y sedimentos de tierra para su datación mediante radiocarbono y luminiscencia óptimamente estimulada (OSL). También se procedió a revisar la cultura material asociada a las fases "posromanas". Con el fin de contrastar los datos obtenidos, se abrieron dos 
pequeños sondeos en diferentes zonas del yacimiento, en los cuales se tomaron nuevas muestras para datar por radiocarbono. Asimismo, se realizó un estudio geológico de los distintos materiales pétreos utilizados en los muros. Como complemento a estas iniciativas, se realizaron prospecciones geofísicas puntuales mediante georradar y espectrometría de rayos gamma in situ en dos zonas del yacimiento así como un levantamiento fotogramétrico a cargo de Juan Ortiz Sanz (USCAN3D - USC). Para dicho levantamiento se combinaron fotografías tomadas con pértiga y otras desde un dron Phantom III con altura media de vuelo de $60 \mathrm{~m}$, y procesadas con software Agisoft Photoscan ${ }^{\circledR}$.

La información proporcionada por estos recientes trabajos permite cambiar radicalmente nuestra visión acerca de las fases "posromanas" del yacimiento. En este artículo pretendemos mostrar de forma sintética los resultados de dichas investigaciones para posteriormente realizar, con base en los mismos, una revisión de la secuencia de ocupación del yacimiento y apuntar una serie de reflexiones respecto a la misma. No incidiremos en explicar en detalle las cuestiones relacionadas con la lectura de paramentos ya que están publicadas en Blanco-Rotea et al. (2015), aunque sí revisaremos la cronología propuesta entonces.

\section{REVISIÓN DE LA CULTURA MATERIAL RECUPERADA EN ANTERIORES INTERVENCIONES}

Durante las excavaciones desarrolladas en los años 1981-2010 se recuperaron algunos materiales (cerámicos, vítreos y metálicos) que excedían la periodización tradicionalmente propuesta para el asentamiento militar romano (Caamaño Gesto et al. 2000, Caamaño Gesto y Fernández Rodríguez 2006). En una primera fase de trabajo decidimos llevar a cabo una aproximación al estudio de estos materiales adscritos a los periodos tardoantiguo y medieval, analizando los contextos arqueológicos en los que aparecieron y revisando la cronología propuesta en trabajos anteriores en relación con nuevos estudios peninsulares en esta materia. $\mathrm{Al}$ igual que en los restos de los análisis llevados a cabo, nuestro objetivo era intentar ordenar la información relativa a estos contextos y datarla de forma absoluta.

\subsection{Aproximación a la cerámica y vidrios posromanos}

Como complemento al anterior estudio de López Pérez (2006), se examinaron las cerámicas de importación correspondientes a las campañas de 2006-2009, depositadas en el Museo Arqueolóxico e Histórico da Coruña. Tal y como establecía esta última autora, parece que ninguna de las formas de terra sigillata hispánica transicional (TSHT) documentadas hasta la fecha en el yacimiento (8T, 35T, 37a, $15 / 17 \mathrm{~T}$ y 50 ) supera la primera mitad del siglo IV d.C., con excepción de dos individuos procedentes de los talleres del valle del Duero y fechables a partir de la segunda mitad de esta centuria (CID06-21-23, CID09-99). Más amplia es la cronología ofrecida por las piezas de terra sigillata africana D (TSAD, formas Hayes 59, 61 A, 91, 103B) y focense tardía (TSFT), que se enmarcan entre este último momento y mediados del siglo VI d.C. A este mismo horizonte parecen pertenecer los escasos fragmentos documentados de ánforas estriadas del Mediterráneo Oriental.

Resulta llamativo también que la mayor parte de los vidrios tipológicamente identificados (Isings 67, 96, 101, 106c, 118) se encuadren en un momento cronológico avanzado (siglos IV-VI d.C.), siendo muy probablemente producidos en talleres locales o regionales fundados en el periodo inmediatamente anterior (Caamaño Gesto 1990, Vázquez Martínez 2000).

Desgraciadamente, carecemos de datos estratigráficos que nos permitan analizar la evolución de la cerámica común durante los periodos tardoantiguo y altomedieval. Sabemos que las producciones de época romana son muy semejantes a las de la cercana Lucus Augusti (Lugo) (Barbazán Domínguez et al. 2015, Caamaño Gesto y Fernández Rodríguez 2006: 172-173, Bartolomé Abraira 2015, Fernández Fernández y Bartolomé Abraira 2016). Una breve inspección de los materiales exhumados en 2006, que será necesario ampliar en futuras ocasiones, nos permitió distinguir posibles cerámicas lucenses tardías -alcanzarían en algunos casos la segunda mitad del siglo V d.C.-, así como otras piezas cuya producción se enmarcaría quizá en los siglos VI-VII d.C. (CID06-186).

Asimismo, varias memorias de excavación recogen piezas genéricamente clasificadas como cerámica "postcampamental" (Caamaño Gesto 1987, 1992a), siendo frecuentemente asociadas a supuestas estructuras "germánicas". Se trataría de ollas, botellas, jarras, cuencos y vasijas de almacenamiento de factura muy tosca, pastas poco cuidadas y presencia en algunos casos de fragmentos de otras cerámicas o vidrios a 


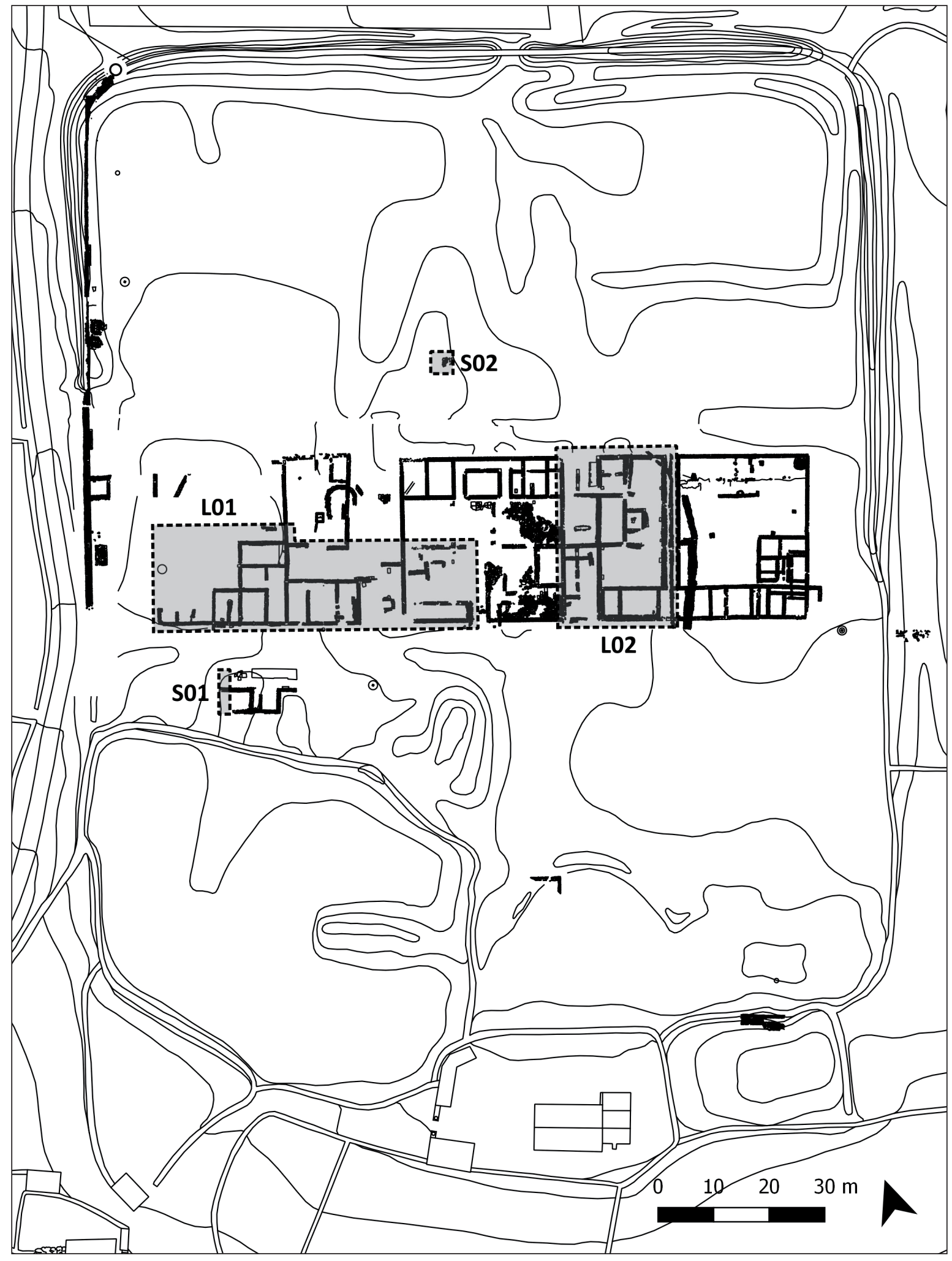

Figura 2. A Cidadela, planimetría tras la intervención de 2016 con indicación de los sectores donde se realizó la lectura de paramentos (L01 y L02) y los sondeos excavados (S01 y S02). 
modo de desgrasante, aunque este hecho no ha podido ser corroborado. De igual modo, la memoria técnica de la campaña de 2006 menciona el hallazgo de dos fragmentos de un recipiente globular con esmalte vidriado en su interior que habría sido identificado como una "producción califal", así como el borde de una olla de "cronología altomedieval” (Ramil González 2007). El mal estado de conservación de ese fragmento cerámico vidriado, así como su escasa representatividad, genera dudas sobre su verdadero origen y cronología. Una revisión premilinar de estos conjuntos ha permitido como novedad identificar material cerámico claramente plenomedieval (siglos XI-XIII), principalmente en la campaña de 1991. Se trata de bordes oblicuos biselados y de protopestaña de pastas gris perla (figs. 3 y 4), similares a los localizados en otros puntos de Galicia (Cid 91/208), como Santiago de Compostela, pero también de pastas marrones como los localizados en A Coruña (Cid 91/1174, Cid 91/314, Cid 09/700, Cid 91/555) (Alonso et al. 2013, Bello et al. 2008). A su vez, esta revisión ha permitido identificar cerámica común, no coincidente tipológicamente con las formas plenomedievales ni con formas romanas, con bordes facetados hechos a mano o bordes apuntados verticales con cepillado vertical u oblicuo (Cid 91/311), que nos pueden estar remitiendo a momentos altomedievales. Así lo indica su similitud con producciones localizadas en la ciudad de Vigo, en concreto con las producciones micáceas de tradición indígena y su olla de borde vertical, encuadrable entre los siglos V y VIII (Fernández Fernández y Bartolomé Abraira 2016).

\subsection{Metales}

Tampoco los objetos metálicos del yacimiento han sido publicados de forma monográfica en anteriores trabajos, pero existe un conjunto de piezas de notable interés que se ha asociado a sus fases más tardías, sobre el que haremos una breve revisión, aun siendo conscientes de que no han sido hallados en contextos arqueológicos estratigráficamente bien datados.

Entre los elementos de adorno personal, destaca en primer lugar una fíbula de bronce de tipo Vyškov con goterón y asiento de la aguja en hierro (fig. 5.5.; Caamaño Gesto 1984). Solo conocemos un paralelo en la península ibérica, en el Castillón de Tábara (Zamora), que puede datarse en el siglo V d.C. (Sastre Blanco y Catalán Ramos 2012: 203-204, Sastre Blanco et al. 2015: 68-71), pudiendo encuadrarse nuestro ejemplar en el subtipo Bratei. Igualmente llamativa es otra fíbula de hierro de arco simple recuperada en 1996, cuya cronología sería de la segunda mitad del siglo V d.C. (fig. 5.4 = CID96-M57; Fernández Rodríguez 1997).

También han aparecido varios elementos correspondientes a hebillas de cinturón. Así, se recuperó en 1983 una aguja o hebijón de base escutiforme (fig. 5.2; Caamaño Gesto 1987, López Quiroga y Martínez Tejera 2017: 260), un modelo antiguo que podría datarse a partir del primer tercio del VI d.C. (Azkarate Garai-Olaun 2006: 409-410, Ripoll 1991: 113). En este mismo contexto se documentó un fragmento del broche decorado de una hebilla de bronce con mucha aleación de plomo (fig. 5.3) que sin embargo no se relaciona tipológicamente con la mencionada aguja.

En 1991 se halló una placa articulada de bronce con su hebijón (fig. 5.1, Caamaño Gesto 1992a). De acuerdo con su morfología y decoración incisa, estamos ante una pieza de procedencia aquitana producida entre finales del siglo VI d.C. y mediados del VII d.C. -Merovingio Reciente I- (Azkarate GaraiOlaun 1993, 2007). Más complicado resulta clasificar otras tres hebillas de hierro documentadas durante las campañas de 1996 (CID96-M189A y B) y 2007 (CID07-153, CID07-182) en los llamados "niveles germánicos" (Fernández Rodríguez 1997, Ramil González 2007). El primer elemento es una sencilla pieza de forma elíptica y sección cuadrangular que conservaba in situ una aguja de sección circular. Las otras dos piezas parecen ser broches de hebillas de cinturón, pero se encuentran en un avanzado estado de oxidación que las hace casi irreconocibles.

Por último, consideramos que la datación en los siglos IV-V d.C. de dos puntas de lanza halladas en 1983 y 1996 a partir de ciertos paralelos en las necrópolis del Duero (Caamaño Gesto et al. 2000: 285) resulta arriesgada. Esta clase de armamento se resiste aún hoy día a cualquier intento de sistematización crono-tipológica, existiendo formas similares a las de Cidadela en contextos de época romana (Bishop y Coulston 2006, Feugère 2002: 169-171).

\subsection{Discusión}

Uno de los grandes problemas que, en su conjunto, presentan todos los materiales referidos es la relativa indefinición de los contextos arqueológicos en los que fueron hallados. Como ya comentamos en otra ocasión, las intervenciones en las que muchas de estas piezas fueron recogidas datan de varias décadas atrás, en las que se empleaban otras metodologías de 


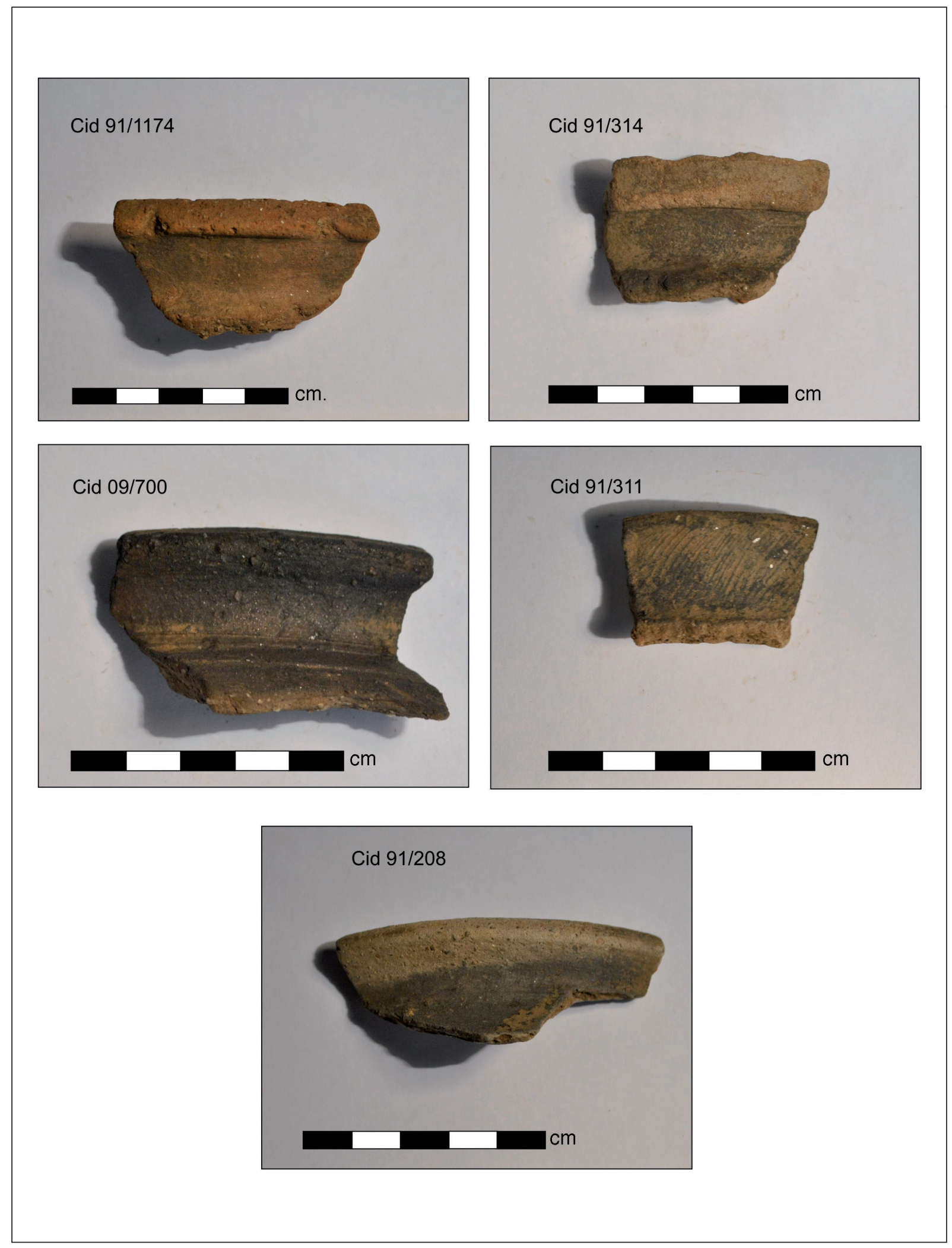

Figura 3. Cerámica de época plenomedieval de la campaña de 1991. Fotografías de algunos bordes representativos. 


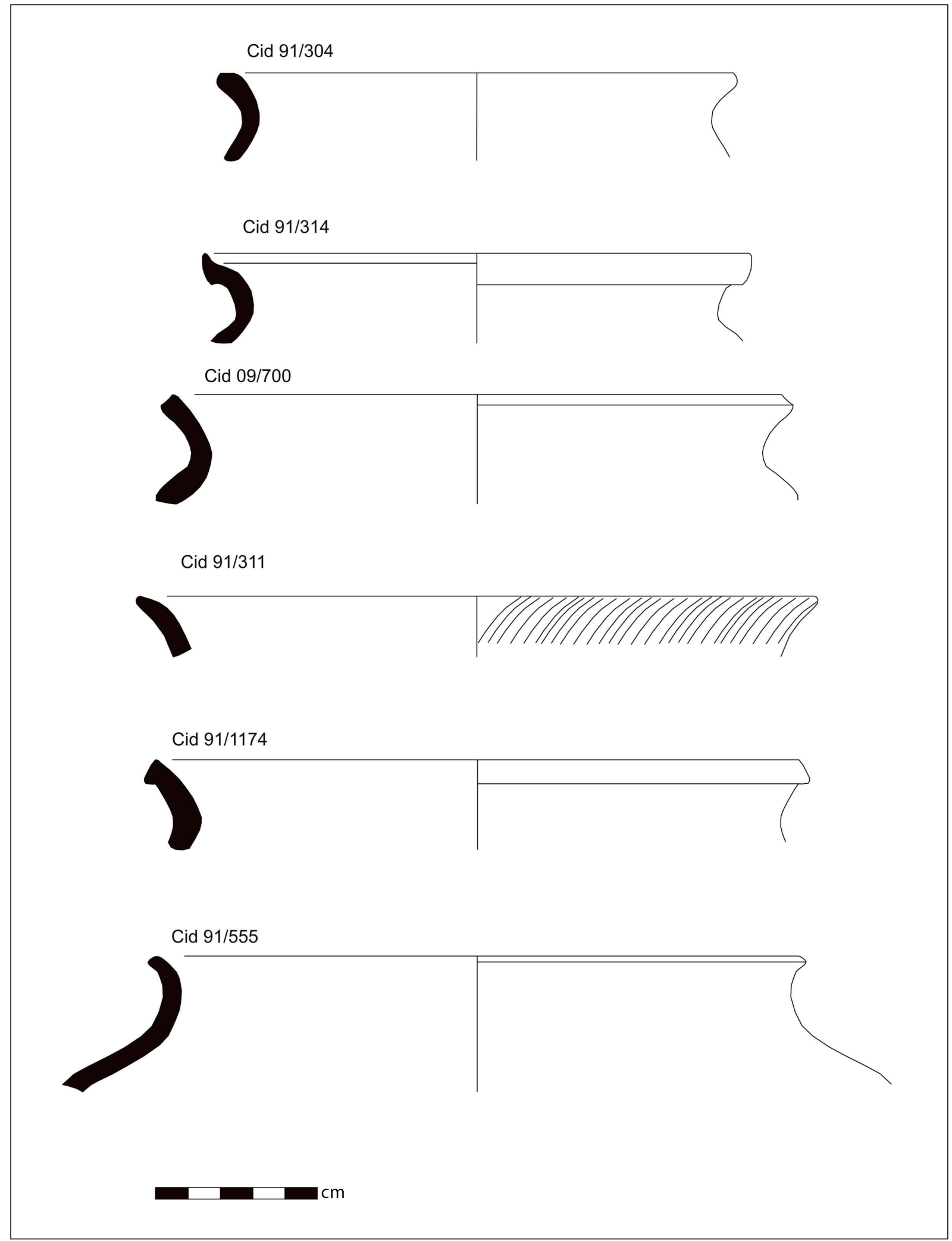

Figura 4. Dibujos de perfiles de cerámica de época plenomedieval de la campaña de 1991. 


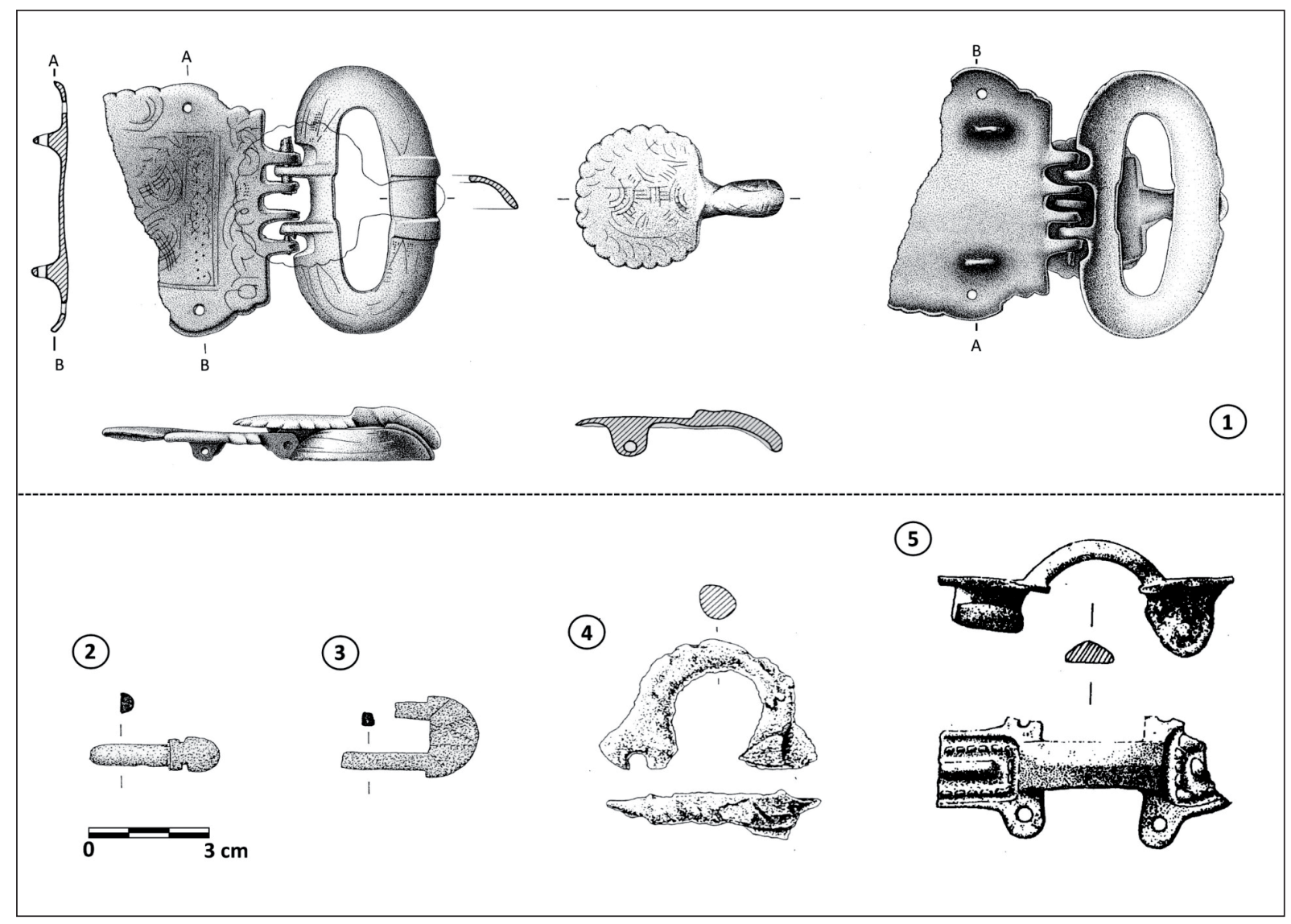

Figura 5. Elementos metálicos de adorno. Placa articulada de bronce con hebijón (1) hallada en 1991 (Anxo R. Paz en Caamaño 1992). Aguja de base escutiforme (2) y placa de cinturón (3) recuperadas en 1983 (Xosé Lomba en Caamaño Gesto 1987). Fíbula de hierro (4) documentada en 1996 (Anxo R. Paz en Fernández Rodríguez 1997). Fíbula tipo Vyškov (5) registrada en 1981 (Xosé Lomba en Caamaño Gesto 1984).

excavación en ocasiones pre-estratigráficas (BlancoRotea et al. 2015: 70-71). Las memorias de excavación reflejan una excesiva simplificación estratigráfica, tendiendo a agrupar los distintos depósitos -nunca descritos- en tres niveles estandarizados: romano (III), abandono y ocupación "germánica" (II), alteraciones posteriores (I). En su mayoría, las piezas referidas se han adscrito al segundo nivel, que se ha considerado un paquete revuelto dentro del cual es posible encontrar elementos de cultura material claramente romanos -p. ej. sigilatas altoimperiales- junto con piezas como las descritas con anterioridad, datadas en momentos posteriores situados entre los siglos IV y VII (datación que, como veremos, coincide con algunos de los horizontes datados en la estratigrafía muraria). Tan solo la documentación del sector excavado en 2006, especialmente rico en evidencias materiales y constructivas, permite definir la procedencia de casi todas las piezas "posromanas" en su contexto estratigráfico, razón por la que, como veremos, ha sido escogido como una de las áreas prioritarias en nuestro estudio.

En todo caso, la revisión de materiales muestra claramente la presencia de un nutrido grupo de piezas datables entre los siglos IV y VII d.C., así como otro grupo de cerámicas de cronología plenomedieval que hasta la fecha habían pasado inadvertidas. Y sobre todo, esta revisión nos ha permitido poner de relieve la existencia de una compleja secuencia estratigráfica más allá de los niveles preconcebidos, algo ya apuntado pero no manifiestamente expresado en 1996 (Fernández Rodríguez 1997). Sin embargo, como ya señalamos, todos estos materiales posromanos requieren un estudio más detallado y exhaustivo que los realizados hasta la fecha, por lo que los datos aquí expuestos solo pueden emplearse como hipótesis para apuntalar o no la información obtenida mediante 
el estudio de la estratigrafía muraria, de los pocos materiales hallados en su contexto, y de las dataciones absolutas. Como veremos, aunque fueron realizados dos sondeos arqueológicos con la intención de obtener una secuencia horizontal limpia y datada de forma absoluta, los materiales documentados fueron muy escasos y no permiten ampliar la información derivada de intervenciones anteriores.

\section{DATACIÓN ABSOLUTA DE LAS ESTRUCTURAS EXCAVADAS EN ANTERIORES CAMPAÑAS}

El cometido de realizar la lectura estratigráfica de las estructuras excavadas con anterioridad a 2016 fue establecer una nueva secuencia relativa de ocupación del yacimiento. Por motivos operativos, se optó por limitar esta actuación a dos aéreas que presentaban un particular interés para los objetivos del proyecto. El Sector 1 se situó en el espacio occidental de los llamados latera praetorii (fig. 1, L01), comprendiendo fundamentalmente la mitad sur del Edificio 1 y el cuadrante sudoeste del Edificio 3. Esta área comprende el espacio excavado en 2006, donde se había documentado una interesante acumulación de evidencias posromanas. Por su parte, el Sector 2 se emplazó más al este, comprendiendo principalmente el Edificio 4 y el espacio situado entre este y el Edificio 3 (fig. 1, L02). En esta zona se habían documentado los restos de la posible iglesia de "época germánica” (Fernández Rodríguez 1997, Caamaño Gesto y Fernández Rodríguez 2002).

Como ya hemos señalado, una primera versión de la secuencia constructiva obtenida como resultado de este estudio ya ha sido publicada (Blanco-Rotea et al. 2015). Sin embargo, la hipótesis barajada en aquel momento para la datación de dicha secuencia se basaba únicamente en la información aportada por los restos de cultura material identificados hasta entonces y las propuestas de otros autores. Con el fin de ofrecer una seriación cronológica más estricta, fueron tomadas un total de 15 muestras de mortero y sedimentos, de las que 9 se dataron por luminiscencia y 6 por radiocarbono. En las siguientes líneas se ofrecen los resultados de esas dataciones, que presentan un sustancial impacto en la mencionada secuencia.

\subsection{Metodología}

La datación por luminiscencia se realizó por medio de luminiscencia ópticamente estimulada (Optically Stimulated Luminescence u OSL), que permite estimar la edad de morteros como el cociente entre la dosis de radiación absorbida total medida (estimada como dosis equivalente o $D_{e}$ ) por luminiscencia y la tasa de dosis de radiación ionizante de las muestras estudiadas $\left(D_{r}\right)$ y los materiales circundantes. La edad estimada corresponderá al tiempo transcurrido desde la última exposición a la luz de los materiales datados (Aitken 1988), lo que en morteros se produce durante la producción y colocación del mortero como diversos estudios han demostrado (Goedicke 2011, Urbanova et al. 2015, Sánchez Pardo et al. 2017). Las medidas de OSL se realizan en granos de cuarzo extraídos del mortero (Sanjurjo-Sánchez 2016).

Se tomaron 9 muestras de morteros de tierra para su datación por OSL. Las dataciones fueron realizadas en el laboratorio de Luminiscencia de la Universidad de A Coruña. Los detalles de la preparación de las muestras para la datación por OSL así como la metodología utilizada se encuentran detalladas en un trabajo previo al que remitimos (Sánchez-Pardo et al. 2017a).

Se tomaron 6 muestras de mortero de tierra para datación por radiocarbono. En dos de estas la datación se obtuvo a partir de carbones contenidos en ellas, mientras que en las otras se utilizó la materia orgánica que contenían. Las muestras fueron analizadas mediante Espectrometría de Masas acoplada a un Acelerador (Accelerator Mass Spectrometry, AMS) en el laboratorio de Beta Analytic (Florida, USA). Se calibraron las edades con el paquete de software Oxcal 4.1 (Bronk Ramsey 2011) en base a la curva de calibración de Reimer et al. (2013).

\subsection{Resultados}

La edad obtenida por luminiscencia corresponde a la razón entre la radiación absorbida por el cuarzo de una muestra (estimada como De) y la tasa de radiación recibida (estimada como dosis anual). Para estimar la dosis anual se midió la humedad de las muestras y su saturación en agua, dado que el agua atenúa la radiación ionizante (Atitken 1985). El contenido en agua estimado resultó similar para todas las muestras estudiadas (tab. 1). Los análisis elementales de las muestras permitieron obtener las concentraciones de $\mathrm{K}, \mathrm{U}$ y Th en ellas y los materiales de su entorno (roca y sedimento) de modo que se pudo estimar la dosis beta y la gamma (tab. 2). La segunda de estas se estimó 
Tabla 1. Contenido en radionúclidos y en agua estimado para las muestras datadas por OSL. Nota: W, contenido en agua.

\begin{tabular}{|l|c|c|c|c|}
\hline \multicolumn{1}{|c|}{ Muestra } & W (\%) & U (ppm) & Th (ppm) & K (\%) \\
\hline MU141003U01 & $6 \pm 0,6$ & $1,36 \pm 0,07$ & $6,72 \pm 0,34$ & $0,82 \pm 0,01$ \\
\hline MU141003U02 & $6 \pm 0,6$ & $1,60 \pm 0,08$ & $6,82 \pm 0,34$ & $0,98 \pm 0,01$ \\
\hline MU141003U07 & $6 \pm 0,6$ & $1,25 \pm 0,06$ & $3,94 \pm 0,20$ & $0,49 \pm 0,01$ \\
\hline MU141003U11 & $6 \pm 0,6$ & $1,19 \pm 0,06$ & $6,20 \pm 0,31$ & $0,87 \pm 0,01$ \\
\hline MU141003U12 & $5 \pm 0,5$ & $1,86 \pm 0,08$ & $6,37 \pm 0,32$ & $1,20 \pm 0,01$ \\
\hline MU141003U13 & $5 \pm 0,5$ & $1,52 \pm 0,08$ & $4,09 \pm 0,20$ & $1,04 \pm 0,01$ \\
\hline MU141003U14 & $4 \pm 0,4$ & $2,44 \pm 0,12$ & $6,41 \pm 0,32$ & $2,42 \pm 0,02$ \\
\hline MU141003U15 & $6 \pm 0,6$ & $2,46 \pm 0,12$ & $8,39 \pm 0,42$ & $1,21 \pm 0,01$ \\
\hline MU141003U16 & $5 \pm 0,5$ & $2,03 \pm 0,10$ & $3,73 \pm 0,19$ & $0,88 \pm 0,01$ \\
\hline
\end{tabular}

Tabla 2. Tasas de dosis de radiación estimadas para las muestras datadas por OSL.

\begin{tabular}{|l|c|c|c|c|}
\hline \multicolumn{1}{|c|}{ Muestra } & Dr beta (mGy/a) & Dr gamma (mGy/a) & Dr cósmica (mGy/a) & Dr total (mGy/a) \\
\hline MU141003U01 & $0,91 \pm 0,10$ & $0,63 \pm 0,03$ & $0,22 \pm 0,01$ & $1,75 \pm 0,13$ \\
\hline MU141003U02 & $1,04 \pm 0,12$ & $0,55 \pm 0,14$ & $0,23 \pm 0,01$ & $1,82 \pm 0,13$ \\
\hline MU141003U07 & $0,61 \pm 0,07$ & $0,30 \pm 0,01$ & $0,23 \pm 0,01$ & $1,14 \pm 0,13$ \\
\hline MU141003U11 & $0,91 \pm 0,10$ & $0,70 \pm 0,02$ & $0,24 \pm 0,01$ & $1,84 \pm 0,13$ \\
\hline MU141003U12 & $1,22 \pm 0,14$ & $0,73 \pm 0,02$ & $0,21 \pm 0,01$ & $2,16 \pm 0,13$ \\
\hline MU141003U13 & $1,02 \pm 0,11$ & $0,69 \pm 0,02$ & $0,22 \pm 0,01$ & $1,92 \pm 0,13$ \\
\hline MU141003U14 & $2,11 \pm 0,24$ & $0,55 \pm 0,02$ & $0,22 \pm 0,01$ & $2,88 \pm 0,13$ \\
\hline MU141003U15 & $1,33 \pm 0,15$ & $0,91 \pm 0,03$ & $0,26 \pm 0,01$ & $2,50 \pm 0,13$ \\
\hline MU141003U16 & $0,97 \pm 0,11$ & $1,46 \pm 0,04$ & $0,22 \pm 0,01$ & $2,64 \pm 0,13$ \\
\hline
\end{tabular}

tanto a partir de un modelo geométrico como por espectrometría gamma portátil, obteniéndose una relación siempre cercana a 1 entre ambas (entre 0,8 y 1,2). En todas las muestras, salvo en bloques de granito, se observó una baja concentración de $\mathrm{K}$ y U y relativamente baja en Th, lo que repercute en bajas dosis anuales. En los morteros la variación observada es de entre $1,19 \pm 0,06$ y $2,46 \pm 0,10 \mathrm{ppm}$ para el $\mathrm{U}$, siendo de entre $3,94 \pm 0,20$ y $8,39 \pm 0,42 \mathrm{ppm}$ para el Th $\mathrm{y}$ de entre $0,82 \pm 0,01$ a $2,42 \pm 0,02 \%$ para el $\mathrm{K}$ en morteros (tab. 1). Esto indica una relación Th: $U$ cercana al rango de ratios $3: 1$ y $5: 1$, que estarían dentro de lo esperable en condiciones de equilibrio secular de las series de desintegración del ${ }^{238} \mathrm{U}$ y del ${ }^{232} \mathrm{Th}$ para materiales derivados de rocas graníticas y magmáticas ultrabásicas (peridotitas, incluso serpentinizadas), respectivamente (Aitken 1985, Boyle 1982). A pesar de estas similitudes, las dosis anuales estimadas oscilan relativamente entre muestras, siendo de entre $1,14 \pm 0,13$ y $2,88 \pm 0,13 \mathrm{mGy} / \mathrm{a}$ (tab. 2), principalmente debido a las variaciones estimadas en las dosis gamma y cósmica.

A pesar de que, teniendo en cuenta el rango de edad abarcado por la OSL, las muestras se pueden considerar recientes, la señal obtenida para algunas de las muestras fue relativamente elevada, siendo notablemente baja para las muestras U11, U02, U12, U14 y U15 (tab. 3), aunque dentro de lo esperado. Esto implica una relación señal/fondo relativamente elevada. Sin embargo, estas diferencias de señal no se pueden 
Tabla 3. Estimación de De obtenidas para las muestras. Nota: N: número de alícuotas; Error rel.: error relativo; Sobredis.: sobredispersión.

\begin{tabular}{|l|c|c|c|c|c|c|}
\hline \multicolumn{1}{|c|}{ Muestra } & Rango aprox. señal (cts) & $\mathrm{N}$ & $D_{e}(\mathrm{~Gy})$ & Error rel. $D_{e}(\%)$ & Sobredis. (\%) & Modelo \\
\hline MU141003U01 & $1000-14000$ & 42 & $4,12 \pm 0,17$ & 4,2 & $55 \pm 6$ & MAM \\
\hline MU141003U02 & $120-3000$ & 46 & $3,51 \pm 0,43$ & 12,2 & $43 \pm 7$ & MAM \\
\hline MU141003U07 & $300-13000$ & 34 & $0,94 \pm 0,06$ & 6,6 & $54 \pm 8$ & MAM \\
\hline MU141003U11 & $80-1300$ & 41 & $1,50 \pm 0,12$ & 8,3 & $37 \pm 7$ & CAM \\
\hline MU141003U12 & $200-2000$ & 40 & $3,52 \pm 0,17$ & 4,9 & $59 \pm 7$ & MAM \\
\hline MU141003U13 & $500-31000$ & 35 & $1,62 \pm 0,13$ & 7,9 & $38 \pm 6$ & CAM \\
\hline MU141003U14 & $150-2500$ & 34 & $2,33 \pm 0,18$ & 7,6 & $36 \pm 6$ & CAM \\
\hline MU141003U15 & $100-3000$ & 32 & $2,57 \pm 0,23$ & 9,9 & $43 \pm 8$ & CAM \\
\hline MU141003U16 & $150-17000$ & 34 & $2,57 \pm 0,14$ & 5,5 & $16 \pm 5$ & CAM \\
\hline
\end{tabular}

relacionar con las $D$ obtenidas ni con los errores estimados para la $D_{e}$, dado que el coeficiente de relación de Pearson entre señal natural y ambos parámetros apenas alcanza el 0,6. Menos clara entre la $D$ y su error, cuyo coeficiente de correlación es muy bajo. Esto se debe también al uso de diferentes modelos de edad para obtener las $D_{e}$. La señal OSL observada varía además respecto a la velocidad de caída, oscilando entre un blanqueado del $80 \%$ tras estimular la señal natural en algunas muestras durante 2-3 segundos (U01, U02, U11, U12 y U15) y en 1-1,5 segundos (U07, U13, U14 y U16), alcanzándose entre 10 y 15 segundos en las señales más lentas y en 5-10 segundos en las más rápidas.

Se han estimado las $D_{e}$ a partir de un número significativo de alícuotas aceptadas (entre 32 y 46) según los requisitos del SAR. Las distribuciones obtenidas de las $D_{e}$ de las alícuotas medidas han proporcionado distribuciones muy diversas en cuanto a asimetría, dispersión y curtosis. Algunas muestras presentaron distribuciones simétricas con baja curtosis, es decir, elevada dispersión alrededor de la media de la distribución (U11, U13, U14 y 15), o elevada curtosis, lo que implica baja dispersión (U16), siendo las que menor sobredispersión mostraban (ver tab. 4). En otras muestras se observa una mayor asimetría, como en U07 y U12, pero sobre todo en U01 y U02 (con valores de sobredispersión cercanos al 50\%). En función de estas distribuciones y los valores de sobredispersión (tab. 4), se utilizó el Modelo de Edad Central o CAM para aquellas con menor sobredispersión y simetría y el Modelo de Edad Mínima o MAM para aquellas con valores de sobredispersión más elevados y asimetría, según la propuesta de por Galbraith et al. (1999). Los tests de recuperación de la dosis mostraron un buen cociente de recuperación, alrededor de $\sim 1.0$, pero con desviaciones grandes, cercanas al $\pm \sim 0.1$ lo que indica una sensibilidad variable en las muestras. Las $D_{e}$ obtenidas se exponen en la tabla 4.

Las edades resultantes de la datación por OSL indican un amplio rango cronológico para las estructuras estudiadas. En el caso de la muestra MU141003U01 se observa que la edad obtenida es excesivamente antigua. Esto es coherente con la asimetría y sobredispersión de la $D_{e}$ de dicha muestra, que indica un evidente blanqueado parcial de la señal residual del cuarzo en el momento de preparación del mortero, por lo que consideramos que esta edad no debe tenerse en cuenta dentro de la interpretación cronológica del yacimiento. Un comportamiento similar de la señal y las alícuotas analizadas se observa en las muestras MU141003U02, MU141003U07 y MU141003U12, aunque en estos casos, la edad obtenida entra en el rango de las edades esperadas y es coincidente con los resultados de la datación por ${ }^{14} \mathrm{C}$ de otras muestras obtenidas en estructuras vinculadas a las mismas fases constructivas, pero debemos actuar igualmente con cautela.

Las edades de radiocarbono obtenidas también proporcionan dataciones diversas (tab. 5). La datación por medio de carbones proporciona edades para las UEs 15 y 17 que coinciden en una parte del rango obtenido, por lo que podrían ser contemporáneas entre sí. Sin embargo, el resto de dataciones en materia orgánica proporcionan edades más dispares y tardías. Los valores 
Tabla 4. De, DR (dosis anual) y edades obtenidas para las muestras datadas por OSL

\begin{tabular}{|l|c|r|r|r|c|}
\hline \multicolumn{1}{|c|}{ Muestra } & $D_{e}(\mathrm{~Gy})$ & \multicolumn{1}{c|}{$D_{r}(\%)$} & \multicolumn{1}{c|}{ Edad (a) } & \multicolumn{1}{c|}{ Edad d.C. } & Rango \\
\hline MU141003U01 & $4,12 \pm 0,17$ & $1,75 \pm 0,13$ & $2354 \pm 201$ & $339 \pm 201 \mathrm{AC}$ & $540-138 \mathrm{AC}$ \\
\hline MU141003U02 & $3,51 \pm 0,43$ & $1,82 \pm 0,13$ & $1926 \pm 270$ & $89 \pm 270$ & $182 \mathrm{AC}-359$ d.C. \\
\hline MU141003U07 & $0,94 \pm 0,06$ & $1,14 \pm 0,13$ & $825 \pm 110$ & $1187 \pm 110$ & $1077-1297$ \\
\hline MU141003U11 & $1,50 \pm 0,12$ & $1,84 \pm 0,13$ & $807 \pm 87$ & $1205 \pm 87$ & $1118-1292$ \\
\hline MU141003U12 & $3,52 \pm 0,17$ & $2,16 \pm 0,13$ & $1631 \pm 125$ & $381 \pm 125$ & $256-506$ \\
\hline MU141003U13 & $1,62 \pm 0,13$ & $1,92 \pm 0,13$ & $841 \pm 86$ & $1171 \pm 86$ & $1085-1258$ \\
\hline MU141003U14 & $2,33 \pm 0,18$ & $2,88 \pm 0,13$ & $808 \pm 71$ & $1204 \pm 71$ & $1133-1275$ \\
\hline MU141003U15 & $2,57 \pm 0,23$ & $2,50 \pm 0,13$ & $1028 \pm 114$ & $984 \pm 114$ & $869-1098$ \\
\hline MU141003U16 & $2,57 \pm 0,14$ & $2,64 \pm 0,13$ & $974 \pm 71$ & $1038 \pm 71$ & $967-1109$ \\
\hline
\end{tabular}

Tabla 5. Edades de radiocarbono obtenidas por AMS.

\begin{tabular}{|l|r|r|l|c|l|c|}
\hline \multicolumn{1}{|c|}{ Muestra } & UEb & \multicolumn{1}{c|}{ Edad 14C } & Material & \multicolumn{1}{c|}{$\delta$ 13C (\%) } & \multicolumn{1}{c|}{ Código lab. } & Edad cal. d.C. \\
\hline MU150601U01 & 22 & $1590 \pm 30$ & MO & -24.5 & Beta-436841 & $400-545$ \\
\hline MU150601U02 & 17 & $1670 \pm 30$ & Carbones & -24.4 & Beta-412615 & $265-275330-420$ \\
\hline MU150601U03 & 15 & $1660 \pm 30$ & Carbones & -25 & Beta-422616 & $335-425$ \\
\hline MU150601U07 & 108 & $210 \pm 30$ & MO & -25.9 & Beta-412618 & $\begin{array}{c}1645-16851735-1805 \\
1950-\text { post }\end{array}$ \\
\hline MU150601U05 & 114 & $750 \pm 30$ & MO & -25.8 & Beta-412617 & $1225-1285$ \\
\hline MU150601U04 & 115 & $330 \pm 30$ & MO & 25.7 & Beta-436842 & $1465-1645$ \\
\hline
\end{tabular}

obtenidos de $\delta^{13} \mathrm{C}(\%)$ de la materia orgánica utilizada en la datación entran en el rango considerado para restos vegetales del suelo, lo que indicaría que no se han producido transformaciones posdeposicionales en ese material debido a la actividad de organismos o que estas han sido leves, no habiendo incorporación de ${ }^{14} \mathrm{C}$ postdeposicional en proporciones significativas, dado que eso cambiaría la relación $\delta^{13} \mathrm{C}$. Por ello, la edad radiocarbono no debería corresponder a alteraciones posteriores a la colocación de los morteros, y la edad obtenida puede corresponder en realidad al suelo de donde procedían las materias primas, lo que no se corresponde necesariamente con la edad de construcción de las estructuras en donde el mortero fue utilizado o de formación de los derrumbes datados (para el caso de las UEs 15 y 17), en los que posteriormente crecería vegetación aportando el carbono orgánico que habría sido datado en esos casos.

\subsection{Discusión}

A continuación cotejaremos los resultados de todas estas dataciones con la secuencia constructiva previamente publicada (Blanco-Rotea et al. 2015) (figs. 6-7).

Dentro del primer horizonte romano se identificaron cuatro fases en aquel trabajo que, en lo sustancial, no se ven afectadas por las dataciones obtenidas: Fase 0: planificación del fuerte. Fase I: planta original de la fortificación romana. Fase II: ocupación efectiva del fuerte durante la que se realizarían algunas reformas parciales. Fase III: intensa reestructuración del fuerte que altera su planta original.

Desde un punto de vista constructivo, los muros se alinean en sentido norte-sur y este-oeste, la modulación es ordenada, se usa una mampostería irregular-opus incertum- con piezas de tamaño medio, $\mathrm{y}$ en los esquinales e intersecciones de los muros de 


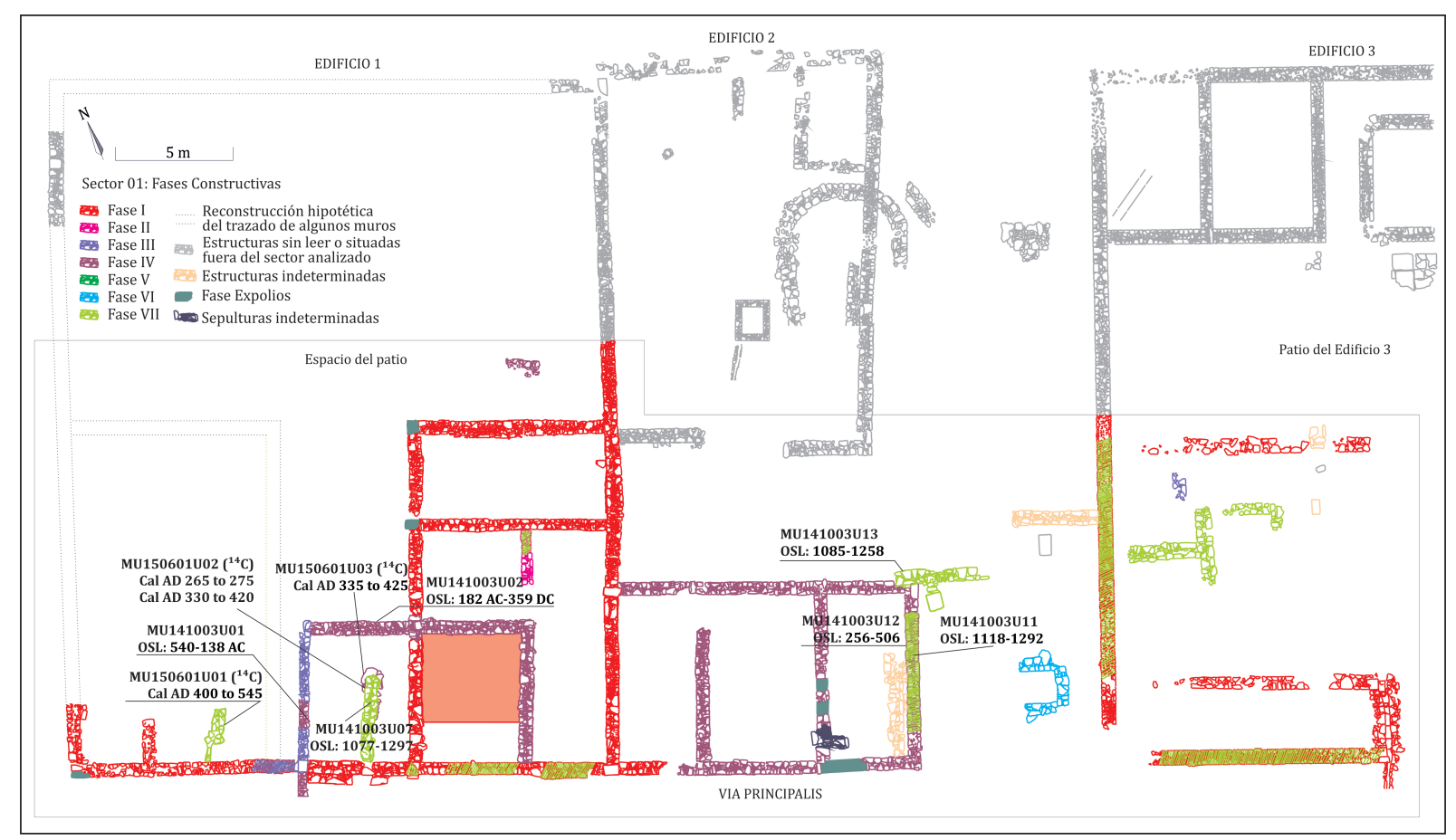

Figura 6. Secuencia constructiva en el Sector 1 con indicación de las dataciones obtenidas.

sillares aparecen piezas molduradas de granito. Además, los materiales se disponen en pseudohiladas, las juntas están enripiadas y presentan mortero de tierra, y se documentan dos caras y núcleo sin tizones. Únicamente en la fase III se emplea teja como ripio y se reutilizan sillares de granito. Las cimentaciones de los muros perimetrales se asientan sobre una capa de gravas, mientras que los muros tabiqueros se disponen a una cota superior. Los pavimentos son de tierra apisonada sobre varias capas de drenaje de grava y piedra, documentándose puntualmente el uso de opus signinum.

Dado que el objetivo de la intervención fue la datación de las fases posromanas, las escasas muestras tomadas en las estructuras de este horizonte no fueron procesadas. La datación más antigua obtenida por OSL (MU141003U01) corresponde al mortero del muro UEM123 perteneciente a la fase $\mathrm{V}$, una reforma del muro UEM011 de la fase III. Sin embargo, el arco obtenido, 540-138 a.C., es una edad excesivamente antigua para este yacimiento. La asimetría y sobredispersión de la $D_{e}$ en dicha muestra indica un blanqueado parcial de la señal residual del cuarzo en el momento de preparación del mortero, por lo que esta edad está claramente sobreestimada y no debe tenerse en cuenta dentro de la interpretación cronológica del fuerte.
Un segundo horizonte tardorromano se relacionó con el abandono del fuerte y su posterior reconstrucción y reocupación parcial. A este periodo pertenece la fase IV, cuyas estructuras se asientan sobre derrumbes de teja terraplenados o pavimentos romanos. Los muros son de mampostería irregular, de dos hojas, con piezas de diversos materiales (peridotitas serpentinizadas, granodioritas y granito), sin tizones y de factura menos cuidada y más irregular que los muros romanos. Inicialmente se dató esta fase en los siglos IV-VI d.C. a partir del conjunto de materiales identificados en los derrumbes excavados en 2006, siendo difícil adscribir con seguridad estructuras a la misma (Blanco-Rotea et al. 2015: 83).

Con la intención de datar de forma absoluta esta fase, se tomaron varias muestras procedentes de depósitos relacionados con los derrumbes de pizarra. Así, el depósito situado bajo este derrumbe, con abundante teja (UEM015, MU150601U03/ Beta-422616), arrojó una datación por ${ }^{14} \mathrm{C}$ de $335-425$ d.C. considerando un intervalo $2 s$ (98\% de probabilidad). El depósito de tierra ubicado sobre este, que sirve de asiento al muro UEM018, ofreció una datación $(2 s)$ de 265-275 y 330-420 d.C. (UEM017, MU150601U02/ Beta-412615). Por su parte, un depósito similar a este, localizado bajo el muro UEM024, ha sido datado en 400-545 d.C. (UEM022, MU150601U01/ Beta-436841) (fig. 6). Es decir, nos 


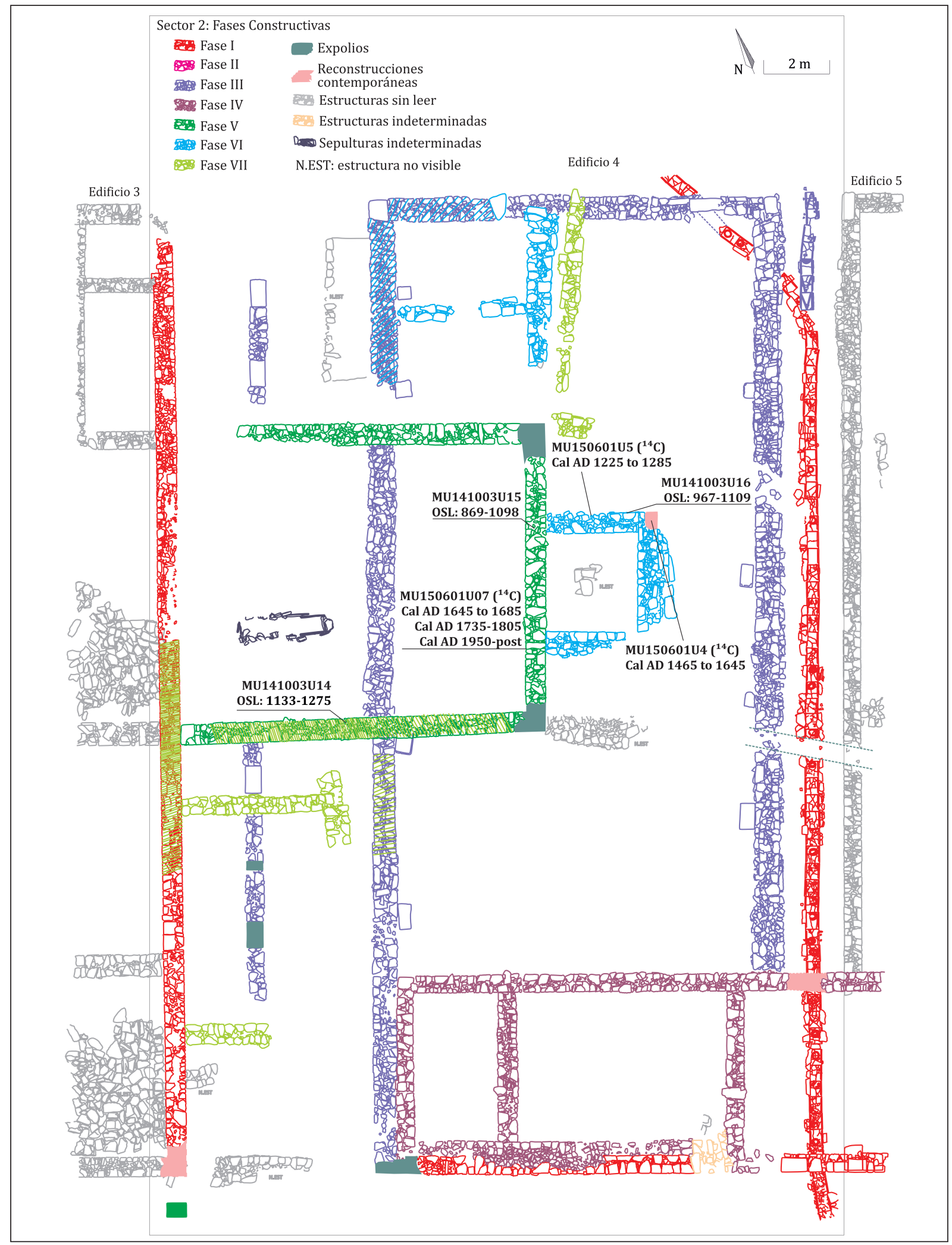

Figura 7. Secuencia constructiva en el Sector 2 con indicación de las dataciones obtenidas.

ISSN: $1133-4525$ ISSN-e: 2255-3924 
encontramos en un horizonte entre los siglos IV-V y primera mitad del VI, espectro también cubierto por la cultura material.

Significativos son los resultados de la datación por OSL del mortero de la UEM051 (MU141003U12), que la encuadran en 256-506. Esta estructura se consideró inicialmente parte de la fase 1 del horizonte romano, pero podría ahora enmarcarse en el proceso general de reforma de la fase III o bien tratarse de una ampliación del Edificio 1 vinculada a la fase IV. Puesto que la estructura se recreció en momentos posteriores, no es posible determinar con exactitud este punto.

Al horizonte tardoantiguo se vincularon dos fases que ahora podemos encuadrar mejor desde un punto de vista cronológico. Durante la fase V se habrían rehabilitado y recrecido muchos de los muros romanos, manteniendo su orientación y doblándose en casos puntuales. Las estructuras presentarían dos caras y relleno, empleándose los mismos materiales que en las estructuras de la fase IV y fragmentos de teja como material de relleno de los muros. Con todo, el módulo de las piezas sería de mayor tamaño y las hiladas más irregulares. La identificación de tizones nos permitió diferenciar definitivamente estos muros de los encuadrados en la fase IV, aparentemente desprovistos de ellos. Estas reformas se extenderían a la práctica totalidad de los edificios excavados.

Se documentaron también muros de nueva planta que, aunque seguían la modulación y orientación romanas, eran más estrechos, no respetaban la división interna de los edificios previos y presentaban su cimentación a una cota más elevada. En concreto, se vinculó a esta fase uno de los edificios de nueva planta que ocupa parte de los Edificios 3 y 4 . Se orientaría en sentido oeste-este y habría sido identificado como posible iglesia.

Hasta la fecha, esta fase se había encuadrado en el siglo VII d.C. de acuerdo con la datación genérica de las piezas metálicas documentadas en anteriores excavaciones arqueológicas. Sin embargo, los resultados de las nuevas dataciones permiten replantear dicha cronología. Por un lado, todas las muestras recogidas en los morteros de junta de los recrecimientos arrojan dataciones similares en las dos técnicas empleadas $\left({ }^{14} \mathrm{C}\right.$ y OSL), moviéndonos entre los siglos XII y XIII (UEM052, MU141003U11: 1118-1292 d.C.; UEM107, MU14100314: 1133-1275 d.C.; UEM114, MU150601U05/ Beta-412617: 1225$1285 \mathrm{dC}$.). Por su parte, la muestra tomada en el edificio de nueva planta (UEM108, MU141003U15) lo sitúa entre 869-1098 d.C. Esto, unido a los resultados de los elementos datados en las siguientes fases, nos permite encuadrar los recrecimientos en un horizonte plenomedieval, mientras que la construcción de este y otros edificios de nueva planta de similares características se situarían en un horizonte altomedieval.

La fase VI también se incluyó en el horizonte tardoantiguo propuesto inicialmente. Se corresponde con varias acciones constructivas (Blanco-Rotea et al. 2015: 86) de las que destacaremos ahora una de ellas por su carácter representativo: la pequeña estancia cuadrangular adosada al muro este del edificio de nueva planta, identificada como ábside. Situada a una cota superior, sus muros tienen una mayor anchura y presentan en las caras internas un aparejo de sillarejo dispuesto en hiladas horizontales. Es destacable el abundante uso de tizones y aunque los muros exteriores están muy arrasados, se observa todavía en su cara este un forrado de sillares de granito en las hiladas inferiores y esquinales, así como de peridotitas y granodioritas en el resto del muro. Las dos hiladas inferiores se apoyan sobre un zócalo también sobresaliente. A diferencia de la fase anterior, los muros se asentaban sobre tierra y presentan dos caras con relleno de tierra y mampuestos. Dado que el ábside no se imbrica con el muro de la posible nave, sino que se apoya en ella, consideramos que no pertenecen a la misma fase constructiva. Su datación mediante OSL (UE114, MU141003U16) lo sitúa en 967-1109 d.C., fecha ligeramente posterior a la de la nave. Por estos motivos, se confirma que esta fase no sería tardoantigua, sino altomedieval.

Todo esto genera un conflicto con el encuadre cronológico de la fase VII, originariamente fechada en época altomedieval de acuerdo con algunos materiales. A ella pertenecen una serie de muros construidos sobre los derrumbes de cubiertas (en los depósitos se observan tanto fragmentos de teja como de lajas de pizarra), pavimentos y estructuras de las fases anteriores. Los muros presentan una anchura irregular, son ondulantes, no guardan un orden estético y carecen de cimentación, rompiendo con la articulación ortogonal de las fases previas. Sin embargo, ahora nos replanteamos esta ruptura, puesto que las dos muestras tomadas en muros de esta fase en el sector 1 han arrojado dataciones que se mueven entre los siglos XI y XIII (UEM018, MU141003U07: 1077-1297 d.C.; UEM053, MU141003U13: 1085-1258 d.C.). Estas fechas coinciden con las reconstrucciones en altura efectuadas en los muros romanos y tardorromanos, por lo que se encuadrarían en el nuevo horizonte plenomedieval. O bien en este momento se llevan a cabo dos tipos de acciones (construcción de estancias de nueva planta y recrecimiento de muros preexistentes) o bien dentro de este horizonte podrían existir diversas fases que aún no somos capaces de diferenciar. 
Dos fases se identificaron en un horizonte posmedieval. La fase VIII se vinculó a una serie de parcelaciones y expolios que afectaron a diferentes zonas del yacimiento, también documentados en los sondeos (vid. infra). Hoy sabemos que la actividad de expolio debió producirse ya en plena Edad Media. De hecho, muchos de los materiales usados en la iglesia parroquial románica (c 1200) situada extramuros del fuerte son romanos (sillares de granito con marcas de diferentes sistemas de elevación, sillares que presentan la misma modulación que los documentados en el fuerte, etc.). Igualmente, en la serie de enlosados que hoy podemos datar en el siglo XIII también se reutilizan materiales anteriores. Estas actividades se habrían extendido hasta prácticamente la actualidad. Una de las muestras recogida en una de la zona de los expolios (UEM115) ha ofrecido una datación de 1465 - 1645 d.C. (MU150601U04/Beta-436842). Cabe señalar que a esta fase se había vinculado también un ancho muro hoy desaparecido por encontrarse a una cota superior a la del Edificio 4. Como veremos, se trata de una estructura muy similar a la documentada en el sondeo 2 (UE107), fechada por ${ }^{14} \mathrm{C}$ en el $895-925$ y $940-$ 1020 d.C. (MU160624U04/Beta-448170).

Finalmente, la fase IX se corresponde a distintas acciones llevadas a cabo en el yacimiento en época contemporánea, que incluyen actividades agrícolas y de pastoreo, reparcelaciones, las propias intervenciones arqueológicas, la construcción de la cubierta y caseta, etc.

\section{ANÁLISIS GEOLÓGICO Y PETROLÓGICO}

Tras la reformulación de las distintas fases constructivas a partir de las nuevas dataciones absolutas, nos planteamos realizar la identificación de los distintos materiales pétreos empleados en cada fase y la determinación de su origen. La identificación mediante análisis petrológico nos permitirá comprobar si algún tipo de roca fue utilizado de forma prioritaria en alguna etapa concreta o por si el contrario, todos se utilizaban indistintamente a lo largo de la historia de la ocupación del lugar. Por su parte, la determinación de la procedencia (local o alóctona) del material pétreo utilizado en la construcción también nos puede ofrecer interesante información sobre la organización, aprovisionamiento y grado de inversión económica de las tareas constructivas en cada una de las etapas de ocupación del yacimiento. Por todo ello se procedió en 2016 a la identificación de las distintas litologías que aquí pasamos a describir.

\subsection{Contexto geológico}

El yacimiento de A Cidadela está incluido en la Hoja 71 de la cartografía geológica nacional del IGME. El contexto geológico es el propio del Dominio de GaliciaTras os Montes, dentro de la Zona Centroibérica del Macizo Ibérico, caracterizado por la presencia de rocas graníticas y complejos metamórficos de distinto tipo asociados a la sutura oceánica durante la Orogenia Hercínica (Arenas et al. 1995). Localmente la estructura más importante es el antiforme de Sobrado, una ventana tectónica en la que afloran rocas metamórficas de grado medio y alto y rocas ultramáficas de origen profundo. En su parte más oriental, este antiforme limita con unos afloramientos graníticos de dos litologías distintas que discurren de forma paralela entre sí en una banda con dirección NNO-SSE. En ambos casos son rocas muy deformadas y que petrológicamente corresponden a granitos de dos micas y, más al E, granodioritas (fig. 8). El yacimiento se localiza entre las peridotitas serpentinizadas del centro del complejo polimetamórfico de Sobrado y las rocas metabásicas que las rodean, compuestas fundamentalmente por granulitas máficas y anfibolitas. Estas serpentinitas aparecen en numerosos afloramientos en la zona. Su aspecto suele corresponder a una roca bandeada, aunque se pueden encontrar muestras homogéneas.

\subsection{Metodología}

En una primera fase de determinación, se observaron varias litologías en los muros del yacimiento: esquistos, pizarras, serpentinitas y granitoides, siendo estas dos últimas las más abundantes. Tras este proceso de identificación en los muros objetos de estudio y su disposición en el entorno, se tomaron 5 muestras de las litologías dominantes en los muros del yacimiento (M-1, M-2, M-3, M-4 y M-5). Así, las rocas más comunes corresponden a dos tipos distinguibles por su aspecto macroscópico:

1) Rocas de aspecto masivo, homogéneo, de grano fino y con coloraciones verdosas, con alguna banda de colores más claros (M-1, M-2 y M-3).

2) Rocas de aspecto granítico de grano grueso a medio con abundancia de feldespatos, aparición de megacristales y presencia de máficos (M-4 y M-5).

A continuación se realizaron análisis químicos y mineralógicos para determinar su composición y mineralogía. La composición química se determinó mediante Fluorescencia de Rayos X (XRF) usando 
un equipo MALDI-TOF, Voyager STR-DE de AB. La mineralogía se determinó mediante difracción de Rayos X (XRD), utilizándose un equipo D5000 SIEMENS. Ambos análisis se realizaron en las instalaciones de los Servicios Xerais de Investigación (SAI) de la Universidade da Coruña (UDC). De cada una de las muestras se realizó una lámina delgada para su análisis mediante microscopio óptico de polarización (Nikon 512005). Asimismo se empleó una lupa Nikon H550S para observar detalles macroscópicos de la textura de las rocas.

\subsection{Resultados}

Para las muestras M-1, M-2 y M-3, los resultados obtenidos en los análisis XRF (tab. 6) muestran valores típicos de rocas básicas en un sentido amplio, serpentinitas con un origen en rocas ultrabásicas (Krauskopf y Bird 1995). La composición mineralógica es rica en antigorita y magnetita y presenta minerales accesorios como el talco o piroxenos ricos en $\mathrm{Mg}$. El estudio visual macro y microscópico permite identificar texturas metamórficas que las categorizan como peridotitas serpentinizadas. Estas rocas son las más habituales en el conjunto del yacimiento (fig. 9).

Las muestras M-4 y M-5 (fig. 9.5 y 9.6) corresponden a rocas graníticas muy deformadas, encontrándose ambas dentro del rango composicional de una granodiorita (Krauskopf y Bird 1995). Debe senalarse asimismo que al interior del propio yacimiento se observó la existencia de afloramientos sucesivos que aparecen como una banda en el sector centro-oriental, al E de la teórica iglesia (vid. infra). La presencia de grandes cristales de feldespatos y, en menor cantidad, de cuarzo, parece indicar el origen de la misma en alguno de los dos tipos de granodiorita (precoz y de dos micas) que afloran en este emplazamiento. Por su parte, la muestra M-5 (fig. 9.6), con grano más fino, posiblemente se relacione con los granitos poco deformados que aparecen al E de la parroquia y que corresponden al denominado granito de Friol (IGME 1981).

\subsection{Discusión}

No se ha constatado un uso diferencial de materiales pétreos en las distintas fases constructivas. Tanto las serpentinitas como los granitos se combinan y se reutilizan indistintamente y en proporciones similares en los muros de las diferentes etapas identificadas. Además en ambos casos hemos podido determinar que se trata de materiales locales, procedentes del área del propio yacimiento o su entorno inmediato.

Diferente es, en cambio, la situación de las pizarras identificadas en el yacimiento, cuya litología es distinta a la de las pizarras propias del Complejo de Órdenes que afloran en la zona y son, por tanto, claramente importadas desde un ámbito supralocal-regional. Estas pizarras aparecen en niveles relacionados con el horizonte "post-campamental" y muchas de ellas se encuentran agujereadas. En ocasiones se relacionan directamente con clavos de hierro y en algunos casos aparecen formando niveles uniformes de derrumbe (Ramil González 2007), motivos por los que se ha considerado que serían usadas principalmente como elementos de cubrición. Puesto que en época romana las construcciones cuentan con cubiertas de teja e ímbrice, se dedujo que estas piezas fueron empleadas con tal finalidad en un momento posterior (Caamaño Gesto y Fernández Rodríguez 2006: 171-172). Sin embargo, como se vio durante la campaña de 1996, la pizarra habría sido usada también como material constructivo en los llamados muros “germánicos” (Fernández Rodríguez 1997:84), sin descartar que fuese parte del generalizado proceso de extracción y reutilización de elementos pétreos procedentes de fases anteriores. De hecho, durante esta misma intervención habrían aparecido fragmentos de pizarra en contextos teóricamente "romanos". Cabe la posibilidad, entonces, de que la introducción de la pizarra sea un fenómeno que debamos ubicar en un momento entre la fase de ocupación militar romana y la construcción de las denominadas estructuras "germánicas", no asociándose, por tanto, de manera directa con estas últimas.

\section{SONDEOS DE LA CAMPAÑA 2016}

Los distintos análisis que hemos presentado en los apartados anteriores (dataciones absolutas, revisión de materiales, análisis geológico y lectura estratigráfica de muros) suponen un importante avance en nuestro conocimiento de las estructuras excavadas a lo largo de varias décadas en el yacimiento de A Cidadela. Sin embargo, seguía siendo necesario la obtención, registro y datación de nuevas secuencias estratigráficas limpias, que sirviesen de contrapunto a los resultados obtenidos con anterioridad, y que permitiesen calibrar la naturaleza, el alcance y la extensión espacial de las ocupaciones posromanas del yacimiento. Por tanto, 


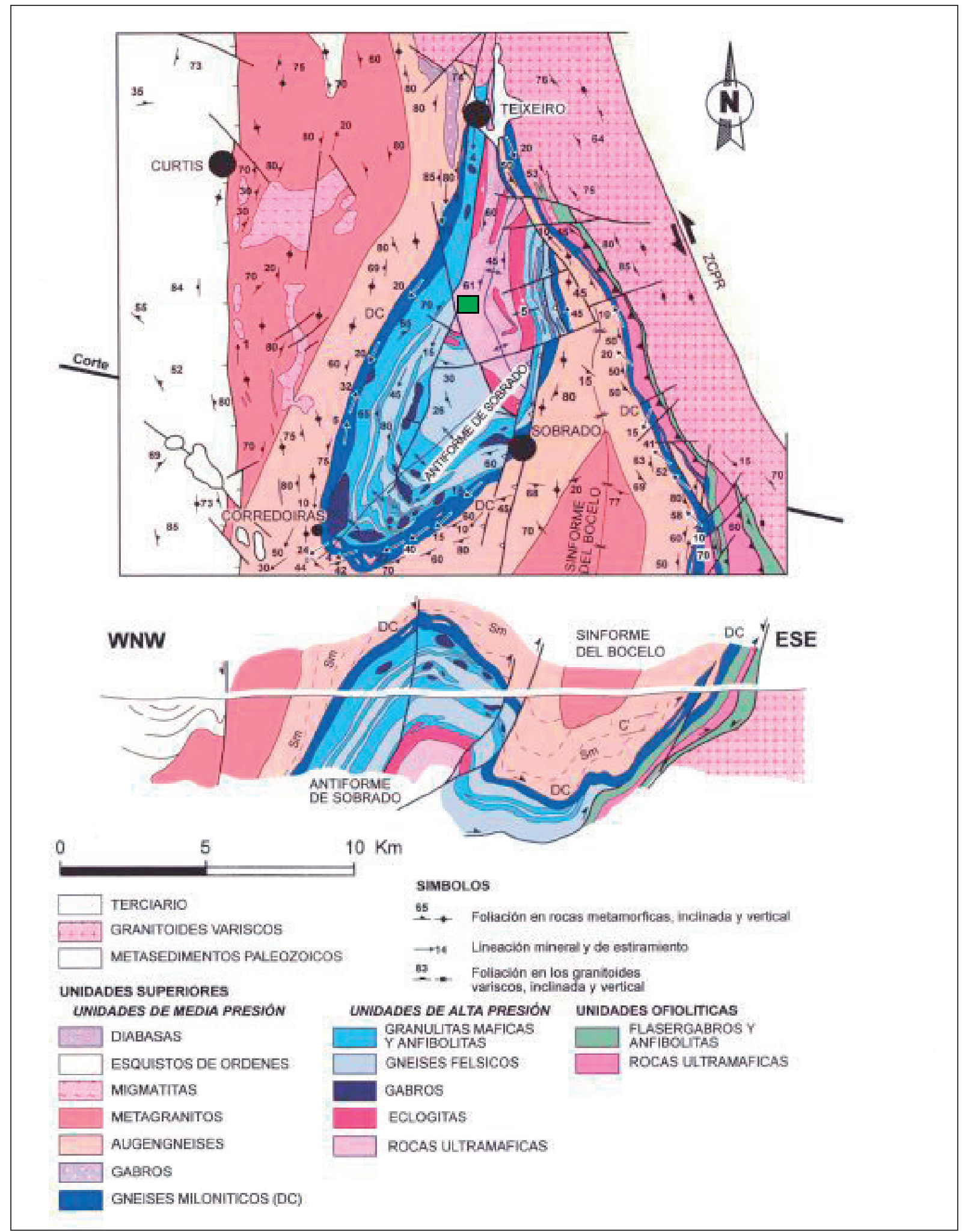

Figura 8. Situación del yacimiento en el mapa geológico del IGME (tomado de Arenas et al. 2016). El yacimiento está representado con un rectángulo verde en el mapa. 
Tabla 6. Composición química por XRF de las muestras recogidas.

\begin{tabular}{|c|c|c|c|c|c|}
\hline & Cidadela M-1 & Cidadela M-2 & Cidadela M-3 & Cidadela M-4 & Cidadela M-5 \\
\hline $\mathrm{SiO} 2$ & 44,000 & 45,000 & 44,500 & 64,900 & 69,200 \\
\hline $\mathrm{A} 12 \mathrm{O} 3$ & 3,700 & 2,800 & 2,600 & 19,000 & 17,300 \\
\hline $\mathrm{K} 2 \mathrm{O}$ & 0,022 & - & - & 8,200 & 5,900 \\
\hline $\mathrm{Na} 2 \mathrm{O}$ & - & - & - & 4,700 & 4,900 \\
\hline $\mathrm{Fe} 2 \mathrm{O} 3$ & 9,900 & 9,700 & 9,400 & 1,400 & 1,200 \\
\hline $\mathrm{CaO}$ & 0,026 & - & 0,014 & 0,580 & 0,460 \\
\hline $\mathrm{MgO}$ & 41,200 & 41,100 & 42,300 & 0,510 & 0,320 \\
\hline $\mathrm{TiO} 2$ & 0,061 & 0,048 & 0,036 & 0,220 & 0,130 \\
\hline $\mathrm{P} 2 \mathrm{O} 5$ & - & - & - & 0,340 & 0,430 \\
\hline $\mathrm{BaO}$ & - & - & - & 0,150 & - \\
\hline $\mathrm{MnO}$ & 0,140 & 0,110 & 0,150 & 0,019 & 0,014 \\
\hline $\mathrm{ZrO} 2$ & - & - & - & 0,011 & 0,009 \\
\hline $\mathrm{SrO}$ & - & - & - & 0,023 & 0,007 \\
\hline $\mathrm{ZnO}$ & 0,013 & 0,015 & 0,012 & - & 0,010 \\
\hline $\mathrm{Rb} 2 \mathrm{O}$ & - & - & - & 0,043 & 0,036 \\
\hline $\mathrm{CuO}$ & 0,010 & 0,008 & 0,009 & 0,007 & 0,008 \\
\hline $\mathrm{SO} 3$ & - & - & - & - & - \\
\hline $\mathrm{Cr} 2 \mathrm{O} 3$ & 0,340 & 0,500 & 0,410 & - & - \\
\hline $\mathrm{NiO}$ & 0,300 & 0,330 & - & - & 0,300 \\
\hline
\end{tabular}

decidimos realizar dos sondeos en el yacimiento en junio de 2016. Teniendo en cuenta estos objetivos, la extensión de ambos sondeos no podía ser excesiva, a fin de no comprometer la calidad del registro. Por otro lado, debían seleccionarse áreas donde se pudiese garantizar la existencia de dichas fases de ocupación, aun teniendo en cuenta lo complicado que ello podía resultar a priori.

En este apartado describiremos los resultados de estos dos sondeos y las dataciones radiocarbónicas realizadas en ellos. Debemos indicar que en ellos apenas se detectaron materiales, que fundamentalmente eran fragmentos de tégula, por lo que desde este punto de vista no aportan apenas información que permita avanzar en la interpretación de la cultura material del yacimiento, aunque sí, en cambio, complementan y refuerzan las secuencias de ocupación del yacimiento previamente identificadas.

\subsection{Sondeo 1}

Se localizó a continuación del sector abierto en 2010 al sur de la antigua via principalis (fig. 1, S01). No solo se habían documentado aquí niveles estratigráficos y estructuras relacionadas con las fases de ocupación posromanas, sino que la apertura de un sondeo en esta área nos permitiría ahondar en la comprensión general de los sectores que se ordenaban alrededor de un gran espacio de tránsito. De este modo, se planteó la apertura de un sondeo de $2 \times 8 \mathrm{~m}\left(16 \mathrm{~m}^{2}\right)$ que, siguiendo los planteamientos y la retícula planimétrica establecida en anteriores intervenciones, integraba parcialmente las cuadrículas K31, K32 y K33.

Pese a lo reducido de su extensión, este sondeo presenta una estratigrafía bastante compleja en la que es posible identificar la existencia de hasta nueve fases (fig. 10): 


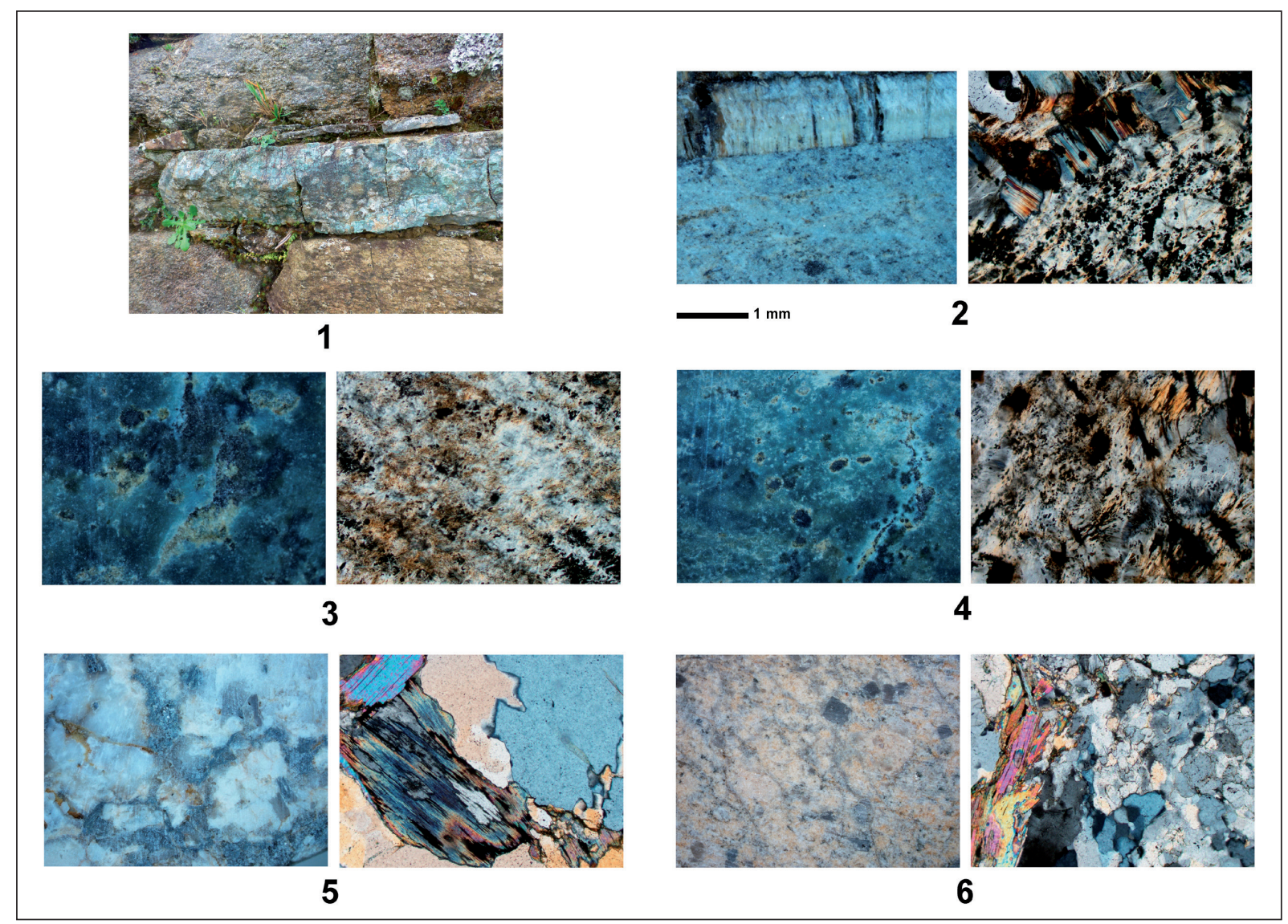

Figura 9. Petrología del yacimiento. 1: detalle de un muro con los dos tipos litológicos principales (serpentinitas y granitoides). 2: muestra 1 (M1), serpentinita. A la izquierda, en lupa, a la derecha al microscopio, en la que se aprecia antigorita, opacos y relictos de piroxeno. 3: muestra 2 (M2), serpentinita, bajo la lupa (izquierda) y al microscopio (derecha). 4: muestra 3 (M3) serpentinita, bajo la lupa (izquierda) y al microscopio (derecha). 5: muestra 4 (M4), granodiorita. En lupa, a la izquierda, se observa cuarzo y feldespatos. Al microscopio, a la derecha, se aprecia cuarzo y micas. 6: muestra 5 (M5), granodiorita. En lupa, a la izquierda, se observa plagioclasa y cuarzo. Al microscopio, a la derecha, se aprecia cuarzo, plagioclasa, microclina y micas.

a) Primera fase constructiva. Está representada por un muro de doble cara (UE019) cuya factura, orientación y dimensiones $(63-65 \mathrm{~cm})$ permiten identificarlo como un muro de carga romano (Blanco-Rotea et al. 2015, Costa-García 2010), que parte de una construcción ya documentada durante la intervención de 2010 (Ramil González et al. 2013).

La estructura divide el sondeo en dos sectores bien diferenciados. Hacia el norte, sobre la zapata del muro (UE026) nos encontramos con un depósito de tierra, gravilla y tejas meteorizadas (UE022) que habría servido de cama para un estrato de matriz arcillosa identificado como pavimento de época romana (UE018). Este suelo parece pertenecer a una reforma dentro del propio periodo romano. Desgraciadamente, la datación radiocarbónica de la muestra de sedimento orgánico MUCID160623U05/Beta448173 obtenida no fue concluyente.

Al sur del sondeo se documenta un panorama completamente diferente, sobre la zapata de cimentación (UE029) se identificó un pavimento arcilloso, amarillo y apisonado (UE025) sellado por un potente derrumbe de teja (UE020). Se trata de una secuencia ya detectada en los años 2006-2010 en las edificaciones situadas a ambas márgenes de la via principalis.

b) Abandono y colapso de la primera fase constructiva. Esta fase se documenta solo en el sector meridional del sondeo y viene representada por el mencionado derrumbe (UE020) y por la disgregación del muro, que atestiguan dos depósitos arcillosos con pequeñas piedras (UE016 y UE027). 
c) Primer expolio. También al sur del sondeo se documenta un corte en los estratos más antiguos (UE024), cuyo relleno (UE023) es un depósito revuelto con materiales muy fragmentados y tierra suelta.

d) Segunda fase constructiva. Esta fase replica la división de espacios ya vista con anterioridad, con el desarrollo de un espacio cubierto hacia el sur y un ámbito de tránsito hacia el norte. Sirve como divisor un muro (UE015) que recrece la antigua estructura romana, un fenómeno ya evidenciado previamente en otros puntos del yacimiento (Blanco-Rotea et al. 2015, Costa-García y Varela Gómez 2011) y que había sido definido tradicionalmente como el epítome de "lo germánico". Sin embargo, la muestra de sedimento MUCID160624U01/Beta-448174 nos remite con claridad a la segunda mitad del siglo XIII (Cal AD 1225 to 1285), en la línea de lo ya visto en el apartado anterior.

Al interior de la construcción se identificó un depósito uniforme de tierra arcillosa y compactada (UE011) que sellaba el derrumbe y el expolio de los estratos romanos, actuando posiblemente como pavimento. Al exterior se detectó otro pavimento que usa mampuestos graníticos romanos en su construcción (UE017), fenómeno ya documentado en 2010 (Ramil González et al. 2013) y que posiblemente se relaciona con una repavimentación posterior de la antigua vía romana.

e) Segundo expolio. A continuación se produjo la extracción de algunas de las piezas graníticas que conformaban este pavimento, pues se localizaron buzadas y desplazadas de su posición original. Rellena la interfaz extractiva (UE028) un depósito de materiales revueltos (UE014) en el que se halló un ladrillo romano que, como otros documentados en 2010 (Carlsson-Brandt Fontán 2011), habrían servido para parchear la vía romana.

f) Colapso del segundo horizonte constructivo. Aunque no sabemos exactamente cuándo tuvo lugar el expolio, todo parece indicar que habría sucedido con anterioridad al derrumbe de la estructura recrecida en el siglo XIII. Este fenómeno se atestigua mediante un pequeño depósito de tierra (UE013) cuya coloración, textura y materiales se corresponderían con el núcleo del muro y un potente derrumbe de piedras y tejas (UE012) que en su caída hacia el sur habrían destruido parcialmente el pavimento interior (UE011).

Con el fin de determinar el momento en que se habría producido el colapso de la mencionada estructura, se dató por radiocarbono una muestra de carbones de la UE013 (MUCID160623U04/Beta448175), cuyos resultados nos remiten con mayor probabilidad a un momento avanzado del siglo IV d.C. (Cal AD 255 to 295; Cal AD 320 to 415). No es la primera vez que se obtienen dataciones de este tipo en contextos teóricamente posteriores y este fenómeno puede relacionarse con el abundante contenido de material reutilizado que presentaba el depósito.

g) Tercer horizonte constructivo. Dos estratos indican la existencia de una última fase constructiva en este sondeo. En el sector norte nos encontramos con un revuelto compactado de tierra, piedras y material latericio que podría haber sido empleado como suelo de uso (UE009). Al sur, otro depósito (UE007) parchea, cubre y nivela los estratos anteriores. Muestra una elevada compactación y plasticidad, así como una casi total ausencia de piedra y teja.

h) Colapso del tercer horizonte constructivo. Dos derrumbes (UE008 y UE010) cubren este nivel de relleno interior. Presentan un buzamiento diferenciado pero idéntica composición, indicio de su coetaneidad. La muestra de sedimento (MUCID160621U01/Beta-448172), tomada en uno de los derrumbes, arrojó un resultado de 1695-1735, 1815-1920, y post 1950, aunque cabe la posibilidad de que esté datando en realidad alteraciones sobre el propio derrumbe.

i) Actividades antrópicas recientes. Sobre estos estratos se hallaron varios depósitos que cubren uniformemente el sondeo (UE006, UE004 y UE003). Son niveles de tierra oscura compactada, con presencia de material latericio muy rodado y piedras. Las bolsadas informes de arcilla roja en los estratos inferiores revelan tal vez los efectos de rozas o quemas controladas, también documentadas en el sondeo 2. Un corte en los mismos (UE005), cuyo relleno (UE002) está compuesto por arena y presenta abundante tornillería, se relaciona con la instalación de la cubierta metálica en el yacimiento en 2000 .

\subsection{Sondeo 2}

En el segundo sondeo se planteó la exploración de un área inédita del yacimiento con el objetivo de comprobar la extensión real de las referidas fases de ocupación posromanas. Su localización exacta en el área de la retentura (fig. 1, S02) se fio al uso combinado 


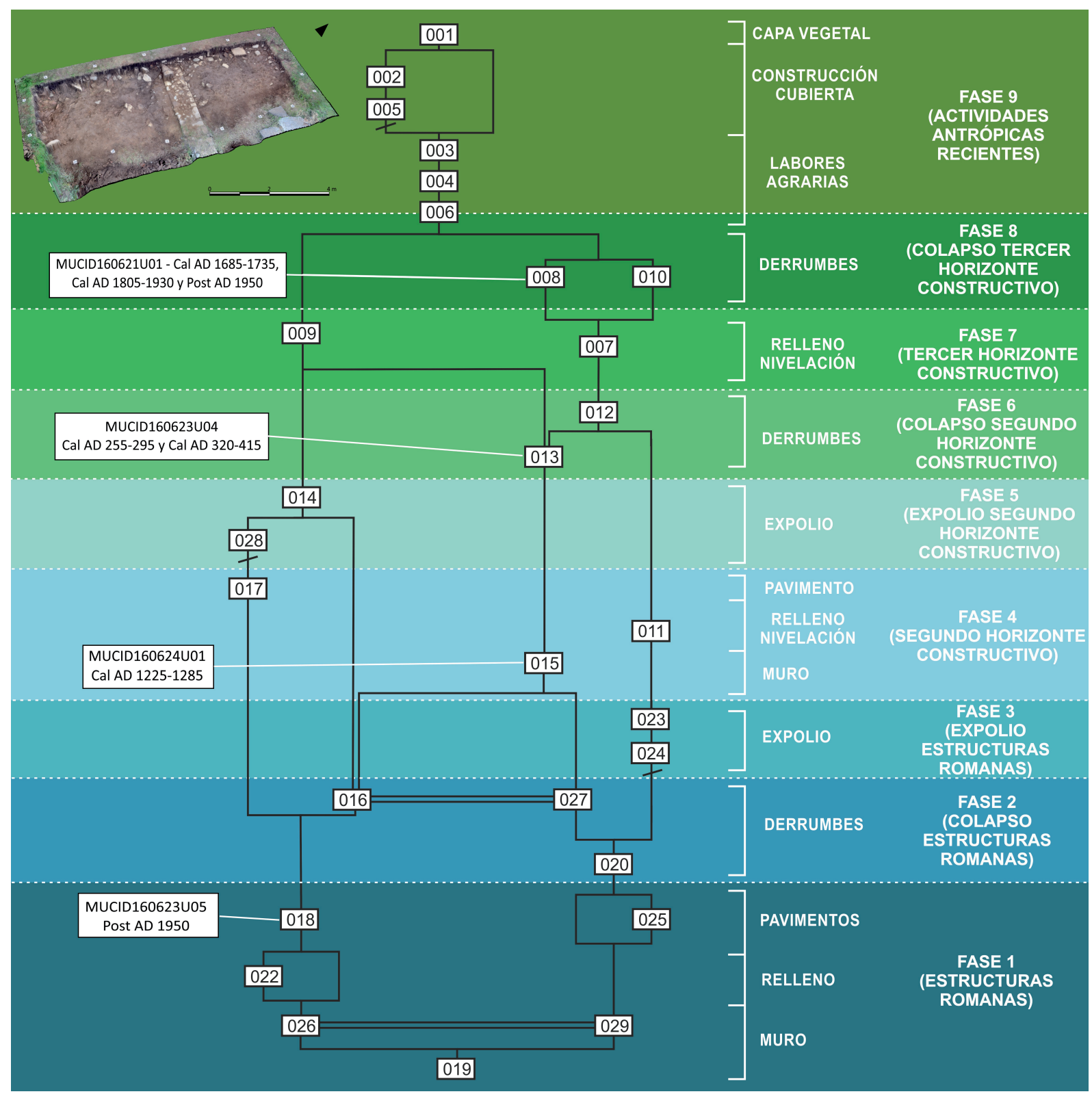

Figura 10. Matrix del sondeo 01 con indicación de las dataciones obtenidas.

de algunos cálculos relativos al ordenamiento del yacimiento en época romana (Costa-García 2011) y a los resultados de la prospección geofísica desarrollada con carácter experimental. Dicha prospección fue realizada por los técnicos del Sistema de Información Territorial de la Universidade de Santiago de Compostela en colaboración con el ingeniero Manuel Pereira. Para esta actividad se utilizó un georradar MALÅ GPR ProEx System con antenas apantalladas de $250 \mathrm{MHz}$ y $500 \mathrm{MHz}$. Ante la imposibilidad de cubrir en su totalidad el área norte del yacimiento en la jornada de trabajo prevista $(0,86$ ha), se optó por definir una serie de transectos (10 longitudinales y 7 transversales) que, en forma de retícula, ofrecerían un muestreo representativo del sector

Un sondeo de $4 \times 4 \mathrm{~m}\left(16 \mathrm{~m}^{2}\right)$ se abrió a caballo entre las cuadrículas T17 y T18 de la retícula original donde las anomalías mostradas por los radargramas nos habían hecho pensar en la existencia de derrumbes $y / 0$ estructuras a una cota prácticamente 


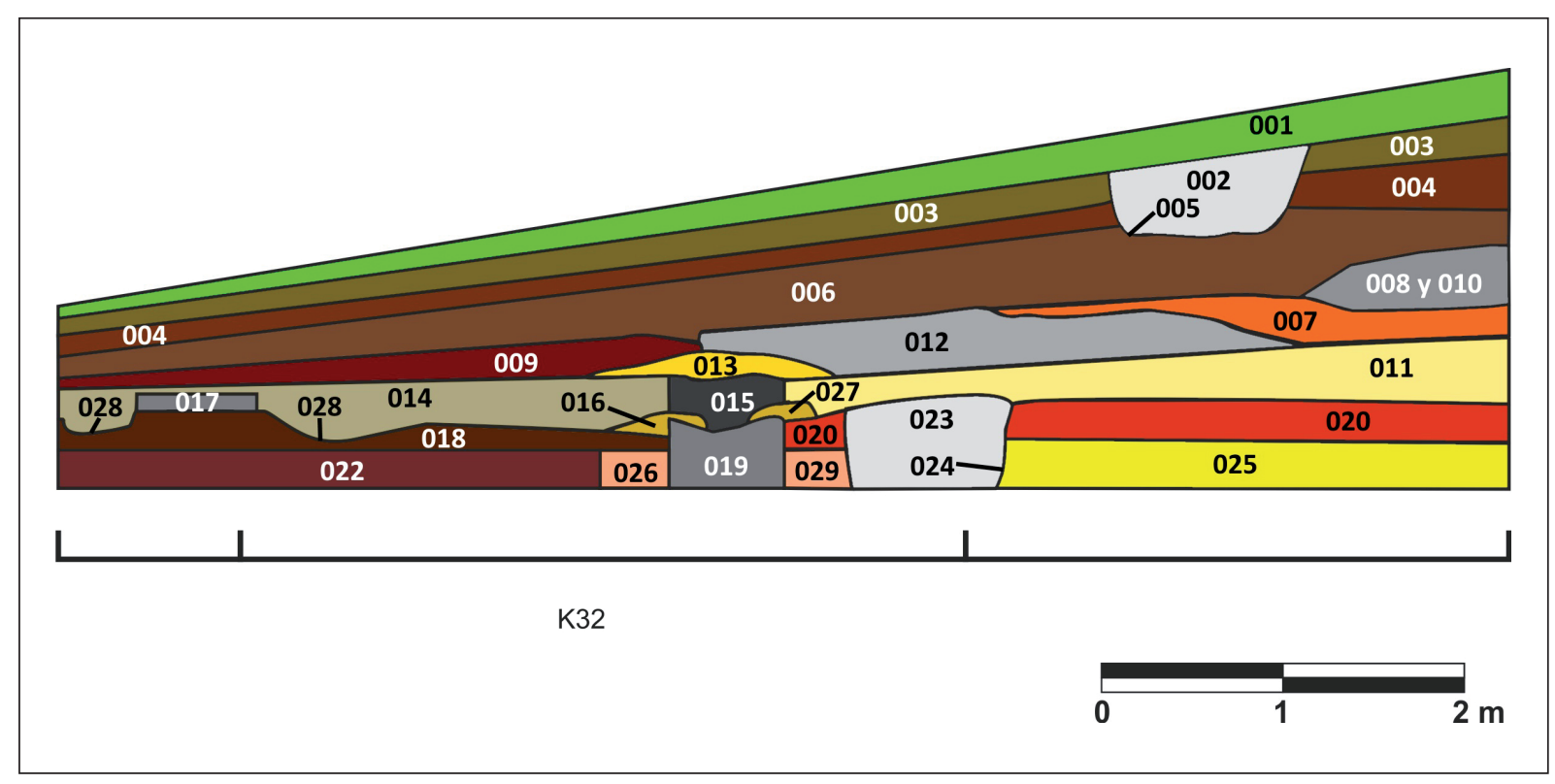

Figura 11. Corte estratigráfico simplificado del sondeo 001.

superficial. Al confirmarse este punto nada más retirarse la cubierta vegetal, se optó por reducir el área de excavación hasta los 4x2 m. Así y todo, no fue posible agotar la potencia arqueológica, de modo que el sondeo hubo de cubrirse tras excavarse unos 50-60 $\mathrm{cm}$ en el extremo sur por 35-40 cm en el norte, documentándose las estructuras más recientes del mismo (figs. 11-13).

a) Horizonte constructivo anterior al siglo $\mathrm{X} \mathrm{d}$. C. Por los motivos señalados, el horizonte más antiguo no se ha podido definir aquí, de modo que esta fase está únicamente integrada por el derrumbe de una estructura muraria que se desarrolla en sentido este-oeste y que tendría una anchura de aproximadamente $1,5 \mathrm{~m}$.

b) Abandono de estructuras anteriores al siglo $\mathrm{X}$. $\mathrm{Cu}$ briendo esta y extendiéndose de forma uniforme por todo el sondeo se detectó un depósito de tierra (UE109-113), que creemos que se genera como consecuencia de un abandono de esta parte del yacimiento. La muestra de sedimento aquí recogida (MUCID160624U09/Beta-448171) ofreció una datación de 905-920 y 965-1025 d.C.

c) Horizonte constructivo del siglo $X$. Sobre este depósito se identificó una nueva estructura, muy deteriorada, un muro de 1,7-1,8 $\mathrm{m}$ de anchura, construido a seco y con piedra de tamaño pequeño-medio. La datación de la tierra extraída entre las piedras (MUCID160624U04/Beta-448170) ofreció una cronología de 895-925 y 940-1020 d.C. La coincidencia con el depósito anterior nos hace pensar que ambas forman parte de una misma acción constructiva, mediante la cual se terraplenan los niveles de abandono anteriores y se construye sobre ellos un muro sin cimentación y de escasa altura.

Como ya indicábamos anteriormente, este muro es similar a una estructura curvada documentada durante las campañas de 1992 y 1993 (Caamaño Gesto 1992b, 1993) y eliminada a fin de poder registrar y dejar a la vista muros más antiguos. Se localizaría al este de la estructura interpretada como posible iglesia y al exterior de su ábside. Hoy pensamos que ambos elementos se relacionan entre sí y con la posible iglesia, que podemos situar precisamente en un horizonte del siglo $\mathrm{X}$ gracias a las dataciones por OSL. Esto coincide con la referencia documental más antigua existente sobre una iglesia de Santa María de Ciadella (Costa-García y Varela Gómez 2011) y quizá la estructura que ahora nos ocupa fuese parte de una cerca o vallado que delimitaría el espacio de la misma.

d) Horizontes de uso post-altomedievales. A ambos lados de la estructura muraria se registraron depósitos de tierra de composición muy similar (UE105, 110, 111) interpretados como un posible suelo formado tras el abandono del yacimiento en un momento 


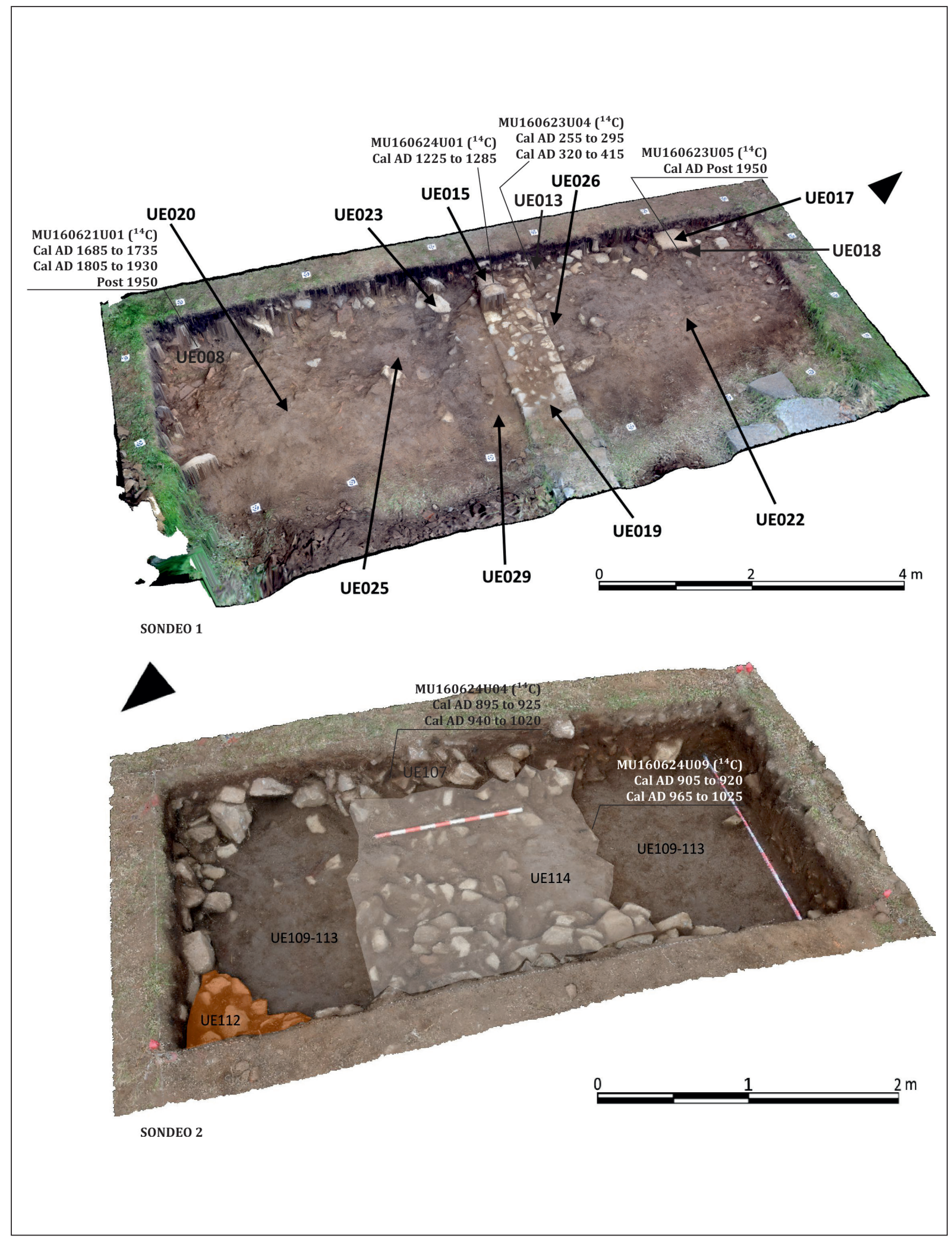

Figura 12. Matrix del sondeo 02 con indicación de las dataciones obtenidas.

ISSN: $1133-4525$ ISSN-e: $2255-3924$ 
posterior a finales del siglo X-inicios del XI, tal vez en época plenomedieval.

Asimismo, en la zona norte del sector se documentó un nuevo derrumbe (UE108) perteneciente a un posible muro que debía tener una orientación Este-Oeste pero que, por encontrarse fuera del área excavada, no fue posible documentar y caracterizar. Sobre este derrumbe se localizó un depósito con abundantes manchas anaranjadas (UE106) que podría ser resultado de rozas, tal vez relacionadas con el laboreo agrícola.

En las capas más superficiales del sondeo se localizarían dos depósitos de piedras (UE104 y UE102) que, por su disposición y buzamiento, creemos se habrían generado como consecuencia del uso del arado. Igualmente, un suelo de tierra orgánica originado por el abandono de las estructuras arqueológicas (UE103) se documentó uniformemente en el sondeo.

\section{REINTERPRETACIÓN DE LA SECUENCIA DE OCUPACIÓN DEL YACIMIENTO}

Con base en todos estos resultados, y a su cotejo con la información previamente disponible sobre el yacimiento, podemos proponer la siguiente secuencia cronológica para el mismo (figs. 8-9):

\subsection{Horizonte romano (siglos I-III d.C.)}

Aunque tradicionalmente se venía ofreciendo una visión del fuerte romano caracterizada por la sincronía de sus diferentes elementos constructivos, el trabajo desarrollado en el seno del proyecto EMCHAHE confirma la hipótesis de un horizonte de ocupación bastante más complejo. Como se recordará, esta hipótesis, apuntada en distinto grado en trabajos anteriores (Caamaño Gesto y Fernández Rodríguez 2002, Costa-García 2010), cristalizó en la caracterización de cuatro fases en la primera propuesta de secuencia constructiva del yacimiento (Blanco-Rotea et al. 2015).

Esta clasificación no se ha visto sustancialmente afectada por los resultados de las dataciones. La excepción la constituye el apéndice sudoriental del Edificio 1, cuya factura se correspondería con la fase III o IV en lugar de la I, teniendo en cuenta los resultados de las dataciones. Es muy posible, sin embargo, que se trate de una reforma sobre una estructura ya contemplada en el planeamiento original del Edificio 1. Aunque el estudio de estas fases no fue un objetivo prioritario de este proyecto, este caso particular subraya la necesidad de ahondar en la caracterización crono-morfológica de las mismas en un futuro próximo.

\subsection{Horizonte tardoantiguo (siglos IV-VI/VII)}

La mayor parte de las evidencias relacionadas con este horizonte se concentran en el sector 1 . Desde el punto de vista de la secuencia edilicia, no solo se constata aquí el levantamiento de determinadas estructuras murarias que implican un reordenamiento de los antiguos espacios construidos, sino también su posterior colapso y derrumbe. Ello nos permite caracterizar con seguridad dos momentos dentro de lo que anteriormente denominábamos Fase IV, y que ahora podríamos definir como fases IVa y IVb. Asimismo, la datación de los depósitos que se encuentran bajo y sobre los derrumbes de pizarra nos permiten apuntar que este lítico probablemente se estuviese usando como material de cubierta ya desde mediados-finales del siglo IV.

Cabe la posibilidad de que estas dos fases no fuesen las únicas dentro de un horizonte que se caracteriza por su amplia cronología. Tanto dataciones como restos materiales apuntan hacia una intensa ocupación de estos espacios entre mediados del siglo IV y al menos inicios del VI. Sin embargo, se trata por el momento de datos demasiado fragmentarios como para proponer una secuencia precisa de la misma, con varias subfases. Desconocemos las motivaciones detrás de esta ocupación, pero la llegada de materiales de importación permite plantear la hipótesis de un grupo humano con cierta capacidad económica, máxime teniendo en cuenta que A Cidadela, por lo que sabemos hasta la fecha, es uno de los escasos yacimientos del interior de Galicia que continúa recibiendo materiales importados hasta el siglo VI.

Resulta también difícil definir en qué momento esta ocupación concluye o se produce una transformación en su función. Carecemos de dataciones que vayan más allá de mediados del siglo VI y a partir de este momento desaparecen también los materiales de importación que nos permitían caracterizar las fases anteriores. La presencia descontextualizada de un diverso conjunto de elementos de atuendo personal -que en algunos casos podrían datarse en el siglo VII- y la existencia de sepulturas que, o bien cortan estructuras de las fases anteriores (una tumba de lajas, UEM044, cortando la UEM047, de la fase IVa) o bien son reutilizadas en otras de momentos posteriores (un sarcófago pétreo infantil en la UEM053), podría ser 


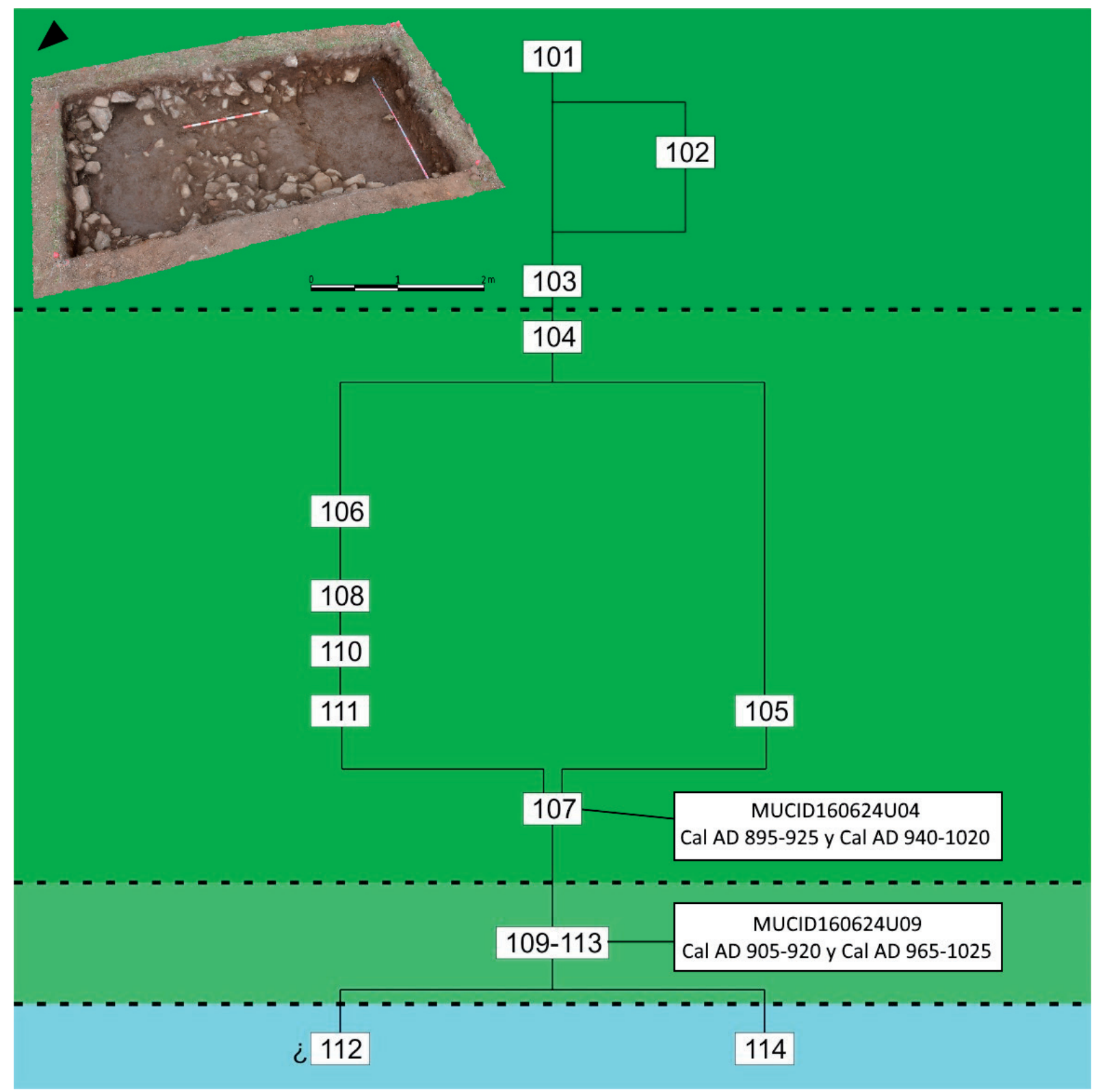

Figura 13. Imagen de los modelos fotogramétricos de los dos sondeos con indicación de las UEs documentadas y las dataciones radiocarbónicas obtenidas en cada uno.

indicativo quizá de la existencia de una necrópolis que se habría visto severamente afectada por las subsiguientes ocupaciones del yacimiento y a la que, tal vez, podrían pertenecer estos materiales.

Por lo que respecta al sector 2 , inicialmente se consideró que el conjunto de estructuras localizadas en el área meridional de los edificios 4 y 5 se correspondería con la fase $\mathrm{V}$, entonces datada en época tardoantigua (vid. supra). Estos muros en ocasiones doblan las estructuras romanas e incluso rebasan la línea de fachada de las edificaciones romanas. Sin embargo, indudablemente conservan el alineamiento ortogonal de las fases anteriores y parecen organizarse respetando la antigua via principalis como espacio de tránsito. Como acabamos de ver, este fenómeno es idéntico al documentado en el sector sur del edificio 1, por lo que cabe la posibilidad de que esta intensa fase de reestructuración se relacione con la Fase IVa y no con la V como 
proponíamos anteriormente. Con todo, por el momento carecemos de dataciones para reforzar esta hipótesis.

\subsection{Horizonte altomedieval (siglos IX-XI d.C.)}

Es fundamentalmente en el sector 2 donde mejor podemos caracterizar la existencia de dos fases que, sin embargo, parecen muy próximas en el tiempo. La mayoría de las muestras tomadas en esta área tuvieron como finalidad el encuadre cronológico de la edificación identificada como posible iglesia, compuesta por una nave rectangular y un pequeño ábside que se adosaba a esta. De este modo, la Fase V se relacionaría con la erección del primer espacio, mientras que la VI lo haría con el segundo. Aunque la secuencia relativa es clara a este respecto, las dataciones obtenidas en uno y otro elemento se solapan en buena medida (869-1098 d.C., MU141003U15 y 967-1109 d.C., MU141003U16, respectivamente), por lo que es posible que los dos procesos constructivos no se separasen en exceso en el tiempo.

Pertenece también a este horizonte el derrumbe de un muro hallado en el sondeo 2, fechado entre el siglo X e inicios del XI. Este posible muro semeja haber sido parte de una estructura mayor cuya disposición en planta parece indicar su función como elemento de delimitación alrededor de la teórica iglesia, quizá marcando físicamente la extensión de la sacraria. Desafortunadamente, resulta imposible relacionar estratigráfica o secuencialmente este muro con las estructuras pertenecientes a nave y ábside. Aunque las dataciones obtenidas nos permitirían un encuadre cronológico en cualquiera de las dos fases señaladas, cabe pensar en una secuencia constructiva general en la que el proceso de reforma y delimitación del espacio sagrado -si se quiere, incluso monumentalización- (Fase VI) sucedería a la erección de la iglesia misma (Fase V).

Una problemática similar presentan las restantes UEM relacionadas con este horizonte, ya que no han sido datadas ni existen adecuados registros del contexto estratigráfico en el que se hallaron. En el sector 2 , ya nos hemos referido a las estructuras documentadas al sur del edificio IV, que hallarían un mejor encuadre en la Fase IV. Por su parte, las situadas al norte de este mismo espacio muestran similitudes formales con el mencionado ábside y se podrían relacionar con el proceso de reforma vivido durante la Fase VI en esta área. Tampoco es posible relacionar estratigráficamente la tumba de lajas situada al interior de la iglesia con los muros de esta, por lo que podría pertenecer tanto a este horizonte como al anterior.

En el sector 1, destaca la presencia de una pequeña estructura cuadrangular que podría identificarse con un ábside (Blanco-Rotea et al. 2015: 86), de ahí su adscripción a la Fase VI. Sin embargo, se trata de un elemento totalmente aislado en un espacio especialmente afectado por alteraciones posteriores y cubierto por vegetación en el momento de la lectura, por lo que sin un trabajo arqueológico más detallado no es posible adscribirla con seguridad a una de las fases del yacimiento.

\subsection{Horizonte plenomedieval (siglos XII-XIII d.C.)}

Este horizonte integra un numeroso conjunto de estructuras que, o bien recrecen muros de fases anteriores, o bien corresponden a muros de tosca factura y nueva construcción asentados sobre antiguos derrumbes y suelos de uso. Hasta seis muros datados tanto en los sectores 1 y 2 como en el sondeo 1 se enmarcan en un rango cronológico que abarca desde finales del siglo XI hasta finales del XIII, solapándose todas las dataciones en el arco 1225-1259. Se evidencia, por tanto, que el sector central del yacimiento vivió en su conjunto una intensa reforma durante el periodo plenomedieval, dando lugar a nuevos espacios que cuentan con su propia organicidad. La cerámica plenomedieval detectada en la revisión de material refuerza esta interpretación. No obstante, como ocurría en el caso del horizonte tardoantiguo, es posible que este fenómeno no se produjese en una sola fase, y tal vez los recrecimientos correspondan a un momento y los muros de nueva planta a otro.

Esta batería de dataciones tiene dos consecuencias inmediatas desde el punto de vista historiográfico e histórico. En primer lugar, se pone de relieve que el conjunto de estructuras genéricamente identificadas como "germánicas" corresponden en realidad a diferentes fases, desde la Tardoantigüedad hasta momentos avanzados del Medievo. Por otro lado, esta intensa reforma de los espacios construidos al interior del recinto coincide con el levantamiento extramuros de un templo románico que, reformado, subsiste hoy en día como iglesia parroquial de Santa María de Ciadella. Cabe pensar entonces en un desmantelamiento y "desacralización" de las anteriores estructuras sitas intramuros para su reutilización con otra finalidad, quizá en relación con la fundación aquí de un asentamiento campesino. 
Tabla 7. listado del total de dataciones absolutas obtenidas para el yacimiento de Cidadela en esta investigación.

\begin{tabular}{|c|c|c|c|c|}
\hline Muestra & Código Laboratorio & Método datación & Material & Rango de fechas d.C. \\
\hline MU141003U01 & & OSL & Mortero de tierra & 540-138 a.C. \\
\hline MU141003U02 & & OSL & Mortero de tierra & 182 a.C. -359 d.C. \\
\hline MU141003U07 & & OSL & Mortero de tierra & $1077-1297$ \\
\hline MU141003U11 & & OSL & Mortero de tierra & $1118-1292$ \\
\hline MU141003U12 & & OSL & Mortero de tierra & $256-506$ \\
\hline MU141003U13 & & OSL & Mortero de tierra & $1085-1258$ \\
\hline MU141003U14 & & OSL & Mortero de tierra & $1133-1275$ \\
\hline MU141003U15 & & OSL & Mortero de tierra & 869-1098 \\
\hline MU141003U16 & & OSL & Mortero de tierra & $967-1109$ \\
\hline MU150601U01 & Beta-436841 & Radiocarbono & Materia orgánica & $400-545$ \\
\hline MU150601U02 & Beta-412615 & Radiocarbono & Carbones & $\begin{array}{l}265-275 \\
330-420\end{array}$ \\
\hline MU150601U03 & Beta-422616 & Radiocarbono & Carbones & $335-425$ \\
\hline MU150601U07 & Beta-412618 & Radiocarbono & Materia orgánica & $\begin{array}{c}1645-1685 \\
1735-1805 \\
1950-\text { post }\end{array}$ \\
\hline MU150601U05 & Beta-412617 & Radiocarbono & Materia orgánica & $1225-1285$ \\
\hline MU150601U04 & Beta-436842 & Radiocarbono & Materia orgánica & $1465-1645$ \\
\hline MUCID160624U04 & Beta-448170 & Radiocarbono & Materia orgánica & $\begin{array}{c}895-925 \\
940-1020\end{array}$ \\
\hline MUCID160624U09 & Beta-448171 & Radiocarbono & Materia orgánica & $\begin{array}{c}905-920 \\
965-1025\end{array}$ \\
\hline MUCID160621U01 & Beta-448172 & Radiocarbono & Materia orgánica & $\begin{array}{l}1685-1735 \\
1805-1930 \\
\text { Post } 1950\end{array}$ \\
\hline MUCID160623U05 & Beta-448173 & Radiocarbono & Materia orgánica & Post 1950 \\
\hline MUCID160624U01 & Beta-448174 & Radiocarbono & Materia orgánica & $1225-1285$ \\
\hline MUCID160623U04 & Beta-448175 & Radiocarbono & Carbones & $\begin{array}{l}255-295 \\
320-415\end{array}$ \\
\hline
\end{tabular}

\subsection{Horizonte bajomedieval y moderno (posterior al siglo XIV)}

A partir de la plena Edad Media es más difícil secuenciar la ocupación humana en el yacimiento. Por un lado, las labores agrícolas y ganaderas o expolios de material afectaron sistemáticamente a muchas de las estructuras más recientes; por otro, con frecuencia estos mismos muros habrían sido desmantelados durante las anteriores intervenciones arqueológicas. Aquellos que sobrevivieron a estas acciones no se encuentran tampoco en buen estado de conservación, al haberse priorizado la consolidación de aquellas estructuras consideradas romanas.

Así y todo, en términos generales no se detectan fases constructivas de entidad semejante a las anteriores. 
Los resultados del sondeo 1 evidencian que sobre las ruinas de las estructuras de época plenomedieval se habrían levantado nuevas construcciones de tosca factura y en otros puntos se han documentado restos de parcelas y muros divisorios. De forma genérica, dichos elementos fueron definidos como Fase VIII, aunque perfectamente podrían pertenecer a distintos momentos históricos.

De idéntico modo, los resultados de las distintas intervenciones contemporáneas en el yacimiento, desde las propias excavaciones hasta las consolidaciones de los muros, pasando por la construcción de la carpa y caseta que hoy se hallan en el yacimiento, se han agrupado bajo la Fase IX.

\section{CONCLUSIONES}

Gracias a las acciones desarrolladas en el marco del proyecto EMCHAHE, hoy sabemos que la secuencia de ocupación del yacimiento de Cidadela a partir del siglo IV es bastante más compleja de lo que inicialmente se había barajado. Frente a la idea tradicional de una importante fase "germánica" del siglo VII caracterizada por la construcción de una iglesia monástica, profundas reformas en las estructuras del antiguo fuerte romano y la utilización de un característico techo en pizarra, hemos podido definir al menos cuatro horizontes de ocupación posteriores al romano que se extienden hasta la actualidad: tardoantiguo, altomedieval, plenomedieval y bajomedieval-moderno. A nivel metodológico, cabe destacar el potencial de la combinación de distintos métodos de datación absoluta (OSL y radiocarbono) que en líneas generales, con un total de 21 dataciones realizadas para esta investigación (tab. 7), han mostrado una fuerte coherencia en sus resultados, reforzando la propuesta cronológica aquí ofrecida.

Aunque los resultados de la intervención han permitido responder algunos de los interrogantes que planteaba el yacimiento, todavía son muchas las cuestiones abiertas e incluso se formulan ahora nuevas preguntas como consecuencia de estas acciones. Este es el reto de futuro que plantea la investigación de este interesante yacimiento arqueológico.

\section{Agradecimientos}

Este trabajo es resultado de los proyectos "EMCHAHE: Early Medieval Churches: History, Archaeology and Heritage", financiado por una ayuda Marie Curie CIG de la Unión Europea (PCIG12-GA-2012-334068);
"TERPOMED: Territorio y poder monástico en la Alta Edad Media", financiado por un proyecto de excelencia de la Consellería de Cultura, Educación e Ordenación Universitaria de la Xunta de Galicia (PG-065, convocatoria Consolidación e Estructuración 2016), y “CONSILIENCIA II", financiado por una ayuda para la creación de Redes de Grupos de Investigación de la Consellería de Cultura, Educación e Ordenación Universitaria de la Xunta de Galicia. Así mismo, la revisión de la cerámica medieval del presente trabajo se ha realizado en el marco del proyecto "Tecnología y producción de la cerámica medieval de Galicia" -MC-PTG-. HAR2015-64441-P -Plan Nacional: Ministerio de Economía y Competitividad, Convocatorias 2015, Proyectos EXCELENCIA y Proyectos RETOS, Dirección General de Investigación Científica y Técnica, Subdirección General de Proyectos de Investigación-2016-2019.

Los autores desean expresar su sincero agradecimiento a Ana Martínez, Adolfo Fernández, Agustín Azkarate y Raúl Catalán, por su ayuda en la identificación de materiales, y a Oria Ferreiro Diz, Celtia Rodríguez González, Tania Rial Figueiras, Mario Fernández Pereiro, Martín Domínguez y Carlos Otero Vilariño, por su fundamental colaboración en la campaña de excavación del yacimiento en 2016.

\section{BIBLIOGRAFÍA}

Aitken, M. J. (1998): An introduction to optical dating. Oxford, Oxford Science Publications.

Alonso Toucido, F.; Prieto Martínez M. P. y Rodríguez Resino A. (2013): “Cerámica en silos. Contextos medievales e modernos na rúa do Franco n ${ }^{\circ} 31$. Santiago de Compostela”. Gallaecia 32: 215-248.

Arenas, R.; Martínez, J.R. y Díaz, F. (2004): “Zona de Galicia-Tras-os-Montes”, en J. A. Vera (ed.), Geología de España: 133-165. Madrid, Sociedad Geológica Española - IGME.

Azkarate Garai-Olaun, A. (1993): "Francos, aquitanos y vascones. Testimonios arqueológicos al sur de los Pirineos". Archivo Español de Arqueología 66 (167-168): 140-176.

Azkarate Garai-Olaun, A. (2006): "Sobre los orígenes cronológicos de los cementerios cispirenaicos de época tardoantigua". Munibe Antropologia - Arkeologia 57: 405-417.

Azkarate Garai-Olaun, A. (2007): "Necrópolis de Buzaga (Elortz)", en VV.AA., La tierra te sea leve: Arqueología de la muerte en Navarra: 195-198. Pamplona, Gobierno de Navarra. 
Barbazán Domínguez, S.; Caamaño Gesto, J. M.; Lozano Hermida, H. y Ramil Rego, E. (2015): "La cerámica común del campamento romano de Cidadela (Sobrado dos Monxes, A Coruña). Campaña 2007”. Gallaecia 33: 189-214.

Bartolomé Abraira, R. (2015): “Cerámica gris fina tardía. Los fondos resaltados de copas y cuencos carenados de Lvcvs Avgvsti”. Férvedes 8: 371-380.

Bello Diéguez, J.M.; Sanjurjo Sánchez, J. y Fernández Mosquera, D. (2008): "Los niveles medievales de la Torre de Hércules: caracterización arqueológica y datación mediante TL y OSL". Férvedes 5: 453464.

Bishop, M. C. y Coulston, J. C. (2006): Roman military equipment from the Punic Wars to the fall of Rome. Oxford, Oxbow Books.

Blanco-Rotea, R.; Costa-García, J. M. y Sánchez-Pardo, J. C. (2015): "Análisis de la evolución constructiva de las estructuras excavadas en el yacimiento de A Cidadela (Sobrado dos Monxes, A Coruña) y propuestas interpretativas sobre sus "fases tardoantiguas"". Estudos do Quaternário 12: 69-93.

Boyle, R. W. (1982): Geochemical Prospecting for Thorium and Uranium Deposits. Amsterdam, Elsevier.

Bronk Ramsey, C. y Lee, S. (2013): "Recent and Planned Developments of the Program OxCal", $R a$ diocarbon 55 (2-3): 720-730. <doi:https://doi. org/10.1017/s0033822200057878>.

Caamaño Gesto, J. M. (1984): “Excavaciones en el campamento romano de Cidadela (Sobrado dos Monxes. Coruña). Memoria preliminar de la campaña de 1981". Noticiario Arqueológico Hispánico 18: 233-254.

Caamaño Gesto, J. M. (1987): Excavaciones en el campamento romano de Cidadela. Campaña de 1983. Santiago de Compostela, Xunta de Galicia.

Caamaño Gesto, J. M. (1989): "Estampillas de la Cohors I Celtiberorum halladas en el campamento romano de Cidadela". Gallaecia 11: 209-229.

Caamaño Gesto, J. M. (1990): "Vidrios hallados en el campamento de Cidadela (Sobrado dos Monxes - A Coruña)". Gallaecia 12: 177-190.

Caamaño Gesto, J. M. (1992a): Excavaciones en el campamento romano de Cidadela. Campaña de 1991. Santiago de Compostela, Xunta de Galicia.

Caamaño Gesto, J. M. (1992b): Excavaciones en el campamento romano de Cidadela. Campaña de 1992. Santiago de Compostela, Xunta de Galicia. Caamaño Gesto, J. M. (1993): Memoria Técnica de Excavación en el campamento romano de Cidadela.
Año 1992. Santiago de Compostela, Xunta de Galicia.

Caamaño Gesto, J. M. (1997): “Sondeos arqueológicos en la muralla del campamento romano de Cidadela". Gallaecia 16: 265-284.

Caamaño Gesto, J. M.; Castro, I.; Ínsua, Ma J.; López Pérez, M ${ }^{\mathrm{a}} \mathrm{C}$.; Vázquez Martínez, $\mathrm{M}^{\mathrm{a}}$ A. y Fernández Rodríguez, C. (2000): "Evidencias materiales en el campamento romano de Cidadela -Sobrado dos Monxes, A Coruña-", en V. Oliveira (Ed.), Arqueología da Antigüedade na Península Ibérica, Vol. VI: 281-292. Porto, ADECAP. Caamaño Gesto, J. M. y Fernández Rodríguez, C. (2002): "Novedades sobre el campamento romano de Cidadela (Sobrado dos Monxes, A Coruña)", en A. Morillo (Ed.), Arqueología Militar Romana en Hispania: 213-226 Madrid, CSIC. Caamaño Gesto, J. M. y Fernández Rodríguez, C. (2006): "Producción y comercialización en el campamento romano de Cidadela", en A. Morillo (Ed.), Arqueología militar romana en Hispania II: Producción y abastecimiento en el ámbito militar: 167-184. León, Universidad de León.CarlssonBrandt Fontán, E. (2011): "El material constructivo latericio en el campamento de Cidadela (Sobrado dos Monxes, A Coruña)". Gallaecia 30: 67-180.

Costa-García, J. M. (2010): "Estudo de paramentos e análise das estruturas exhumadas na "pars nobilis" do campamento romano de A Cidadela (Sobrado dos Monxes, A Coruña)". Gallaecia 29: 191-201.

Costa-García, J. M. (2011): "La castrametación romana en el Noroeste Peninsular: Algunos apuntes para su estudio". Férvedes. Revista de investigación 7: 215-223.

Costa-García, J. M. (2014): "Las primeras intervenciones arqueológicas en A Cidadela (Sobrado dos Monxes, A Coruña". Gallaecia 32: 109-127.

Costa-García, J. M. y Varela Gómez, D. (2011): “A Cidadela después de Roma. Introducción al estudio del yacimiento y su entorno durante el período medieval". Gallaecia 30: 181-194.

Del Castillo, Á. (1934): "El campamento romano de Ciudadela”. La Voz de Galicia 24/6/1934 (num. 16924): 1.

Del Castillo, Á. (1935): "El campamento romano de Ciudadela". La Voz de Galicia 4/1/1935 (num. 17085): 1 .

Fernández Fernández, A. y Bartolomé Abraira, R. (2016). “Cerámicas tardoantiguas en el Noroeste de la Península (Galicia y norte de Portugal): entre la importación y el artesanado local/regional (ss.V-VII)", en: A. Vigil-Escalera y J. A. Quirós (eds.). La cerámica de la Alta Edad Media en el cuadrante noroeste 
de la Península Ibérica (siglos V-X). Sistemas de producción, mecanismos de distribución y patrones de consumo: 69-111 Bilbao, Universidad del País Vasco. Fernández Rodríguez, C. (1997): Excavación arqueológica del campamento romano de Cidadela (Sobrado dos Monxes, Coruña). Campaña de 1996. Informe preliminar. Santiago de Compostela, Xunta de Galicia.

Feugère, M. (2002): Les armes des romains de la République à l'Antiquité tardive. Collection des Hespérides. Paris, Errance.

Galbraith, R. F.; Roberts, R. G.; Laslett, G. M.: Yoshida, H. Y y Olley, H. (1999): “Optical dating of single and multiple grains of quartz from Jinmium Rock Sherlter, Northern Australia: Part 1". Archaeometry 41: 339-364, doi: <https://doi. org/10.1111/j.1475-4754.1999.tb00987.x>.

Goedicke, C. (2011): "Dating mortar by optically stimulated luminescence: a feasibility study". Geochronometria 38: 42-49, dói: <https://doi.org/10.2478/ s13386-011-0002-0>.

Krauskopf, K.B y Bird, D. (1995): Introduction to geochemistry. New York, McGraw Hill.

López Pérez, Ma C. (2006): "La importación de terra sigillata en el campamento de Cidadela (Sobrado dos Monxes, A Coruña)", en: A. Morillo (Ed.), Arqueología militar romana en Hispania II: Producción y abastecimiento en el ámbito militar: 432-437 León, Servicio de Publicaciones de la Universidad de León. López Quiroga, J. y Martínez Tejera, A. M. (Eds.) (2017): In tempore Sueborum. El tiempo de los suevos en la Gallaecia (411-485). Ourense, Deputación de Ourense.

Loscertales De García, P. (1976): Tumbos del monasterio de Sobrado de los Monjes (2 Vol.). Madrid, Dirección General del Patrimonio Artístico y Cultural.

Ramil González, E. (2007): Escavación arqueolóxica e limpeza no campamento romano de Cidadela Sobrado dos Monxes. Memoria técnica 2006. Santiago de Compostela, Xunta de Galicia.

Ramil González, E. y Caamaño Gesto, J. M. (2009): "Escavación e consolidación arqueolóxica no campamento romano de Cidadela", en M. P. García (Ed.), Actuacións Arqueolóxicas, Ano 2007: 81-82. Santiago de Compostela: Xunta de Galicia.

Ramil González, E. y Caamaño Gesto, J. M. (2010): "Escavación, consolidación e limpeza no campamento romano de Cidadela”, en M. P. García (Ed.), Actuacións Arqueolóxicas, Ano 2008: 65-66 Santiago de Compostela, Xunta de Galicia.
Ramil González, E.; Costa-García, J. M. y Caamaño Gesto, J. M. (2013): "Hornos hallados en el campamento romano de Cidadela (Sobrado dos Monxes, A Coruña)". Boletín del Seminario de Arte y Arqueología. Sección Arqueología 77-78: 269-290.

Reimer, P. J., (2013): "IntCal13 and Marine13 Radiocarbon Age Calibration Curves 0-50,000 Years cal BP”. Radiocarbon 55 (4): 1869-1887, doi: <https:// doi.org/10.2458/azu_js_rc.55.16947>.

Ripoll, G. (1991): "Materiales funerarios de la Hispania visigoda : problemas de cronología y tipología”, en P. Perin (Ed.), Gallo-Romains, Wisigoths et Francs en Aquitanie, Septimanie et Espagne: 111132 Rouen, Association française d'archéologie mérovingienne.

Sánchez-Pardo, J. C. y Blanco-Rotea, R. (2014): "Early Medieval Churches. History, Archaeology and Heritage (2013-2017). Marie Curie EMCHAHE project”. The European Archaeologist 42: 83-85.

Sánchez-Pardo, J. C.; Blanco-Rotea, R. y SanjurjoSánchez, J. (2017): "The church of Santa Comba de Bande and early medieval Iberian architecture: new chronological results". Antiquity 357: 1011-1026, doi: <https://doi.org/10.15184/aqy.2017.83>.

Sanjurjo-Sánchez, J. (2016): "Dating historical buildings: an update on the possibilities of absolute dating methods". International Journal of Architectural Heritage 10: 620-635, doi: <https://doi.org/10.1 080/15583058.2015.1055384>.

Sastre Blanco, J. C. y Catalán Ramos, R. (2012): “Un asentamiento fortificado en la tardoantigüedad el castro de El Castillón (Santa Eulalia de Tábara, Zamora)", en J. A. Quirós y J. M. Tejado (eds.), Los castillos altomedievales en el noroeste de la Península Ibérica: 193-211 Bilbao, UPV.Sastre Blanco, J. C.; Fuentes Melgar, P.; Rodríguez Monterrubio, Ó. y Vázquez Fadón, M. (2015): El yacimiento arqueológico de El Castillón (Santa Eulalia de Tábara, Zamora). Un enclave tardoantiguo a orillas del Esla. Valladolid, Glyphos.

Urbanova, P.; Hourcade, D.; Ney, C. Y. y Guibert, P. (2015): "Sources of uncertainties in OSL dating of archaeological mortars: The case study of the Roman amphitheatre "Palais-Gallien" in Bordeaux". $R a$ diation Measurements 72: 100-110, doi: <https:// doi.org/10.1016/j.radmeas.2014.11.014>.

Vázquez Martínez, Ma A. (2000): Los vidrios de Cidadela (Sobrado dos Monxes, A Coruña). Santiago de Compostela, USC. 